\title{
No Mere Tautology: The Division of Labor is Limited by the Division of Labor*
}

\author{
Andrew Smyth ${ }^{\dagger} \quad$ Bart J. Wilson ${ }^{\dagger \dagger}$
}

September 6, 2017

\begin{abstract}
We explore the intersection of growth theory and the theory of the firm with an experiment. Economic growth is possible in our experiment when agents specialize to exploit increasing returns. We find that low opportunity costs are sufficient for Marshallian internal economies, but that Marshallian external economies are slow to emerge in four probing treatment conditions. Transaction costs do not hamper external economies as we anticipated prior to collecting data. When external economies falter, it is because new ideas about the cost and value of more extensive specialization fail to emerge. Ideas are what make further divisions of the division of labor - and thus economic growth - either possible or impossible.
\end{abstract}

Keywords: growth theory, theory of the firm, experimental economics, specialization, increasing returns, transaction costs

JEL: C92, D23, L20, O40

*We are grateful to the Economic Science Institute for funding, Jeffrey Kirchner for his excellent programming, Megan Luetje for her help with recruiting and conducting the experiment, and Jimmy Langner for his research assistance. We also thank Charles Thomas and Gregory Waymire for their helpful comments. Any errors are our own.

$\dagger$ Department of Economics, Marquette University, Milwaukee, WI 53201, email: andrew.smyth@marquette.edu

${ }^{\dagger \dagger}$ Smith Institute for Political Economy and Philosophy and the Economic Science Institute,

Chapman University, Orange, CA 92866, email: bartwilson@gmail.com 
When the market is very small, no person can have any encouragement to dedicate himself entirely to one employment, for want of the power to exchange all that surplus part of the produce of his own labour, which is over and above his own consumption, for such parts of the produce of other men's labour as he has occasion for.

- Adam Smith (1776)

Adam Smith's dictum amounts to the theorem that the division of labour depends in large part upon the division of labour. This is more than mere tautology.

- Allyn Young (1928)

There were cabinets but no cabinet makers in the 18th century Scottish Highlands. Cabinets, Adam Smith informs us, were made by carpenters. ${ }^{1}$ To modern ears, the distinction between carpenter and cabinet maker sounds pedantic. Yet in no small measure, we owe today's immense prosperity to the same force that made carpenter and cabinet maker distinct occupations, namely, specialization.

In Smith's telling, specialization is limited by the extent of the market, that is, demand. The Highlands carpenter cannot devote himself entirely to the production of cabinets, for he would starve for a lack of business. Young (1928) deepens Smith's theorem: Not only can our carpenter not specialize in cabinet making for lack of demand in remote Scotland, he cannot make cabinets for lack of procurable inputs like wood, nails, and tools. In other words, for the occupation of cabinet maker to exist, specialized woodworkers, nail makers, and toolmakers must first exist. The division of labor thus depends upon the division of labor in a mechanistic sense.

Romer (1986, pg.1003) incorporates the insights of Smith and Young: "The creation of new knowledge by one firm is assumed to have a positive external effect on the production possibilities of other firms." Crucially, knowledge is nonrival - it does not wear out. Thus while scientists at AT\&T's Bell Laboratories first acquired scientific knowledge of the transistor, Bell Labs use of this knowledge did not preclude other firms such as Texas

\footnotetext{
${ }^{1}$ See Smith (1776), I.3.2.
} 
Instruments and Fairchild Semiconductor from also using it.

The early history of the transistor illustrates how knowledge gets embodied in products that recast the division of labor. In 1957 in a Fairchild Semiconductor lab furnished with conventional kitchen cabinets and countertops, a young chemist had to blow glass tubing himself to construct transistor diffusion furnaces. Eleven years later, when the same chemist started Intel, Gordon Moore ordered industry standard furnaces off a showroom floor. In the interim Fairchild's success spawned an entire furnace supply industry. ${ }^{2}$ To ape Alfred North Whitehead: Prosperity evolves by extending the number of items we can acquire without making them ourselves.

Specialization is a core tenet of modern growth theory, yet growth theory only touches tangentially upon the boundaries of the firm. The seminal work on firm boundariesCoase (1937) and Williamson (1971), for example - rests on the concepts of opportunity and transaction costs. The Scottish carpenter makes his own nails because it is too costly to trek to Edinburgh to purchase them, and Intel buys furnaces because the opportunity cost of making them is too high. The theory of the firm says little about economic growth. By contrast, in their own bygone eras Smith and Young bridged the modern micro-macro divide as they sought to understand how the boundaries of the firm contribute to the wealth of nations.

We design an experiment to probe the intersection of the theory of the firm and growth theory. Agents in our virtual world can specialize in production which, in turn, can generate opportunities for other agents to specialize in different, complementary production. By design, specialization depends in large part upon specialization, yet transaction costs may hamper the spread of specialization and so limit wealth creation. We cannot completely characterize the transaction costs ex ante, for they are ultimately idiosyncratic to the

\footnotetext{
${ }^{2}$ Thackray, et al. (2015), pp.172-179, 284-285.
} 
experiment participants.

Whereas we must assume specific transaction costs in a model, in the laboratory we create an environment with possibilities and incentives for specialization, populate it with participants, and (assuming that they prefer more money to less) observe whether, and hopefully how, transaction costs impede growth. Our inability to formally state all of the costs to specialization in our environment is a virtue of our experiment vis-à-vis a theoretical model. It gives us the chance to learn something novel, something not foretold by our specific assumptions.

To establish a baseline for our new experimental platform, we first explore whether sufficiently high opportunity costs impede the emergence of specialization. We observe the same environment with low and high opportunity costs and find that low opportunity costs are sufficient for specialization. In further treatments we then consider how specialization begets further specialization and economic growth. Contrary to our pre-experiment expectations, we find that growth is rarely hampered by transaction costs from opportunism. ${ }^{3}$ Instead, it is often impeded because no ideas for further specialization emerge.

Demsetz (1988, pg.157) remarks that "to achieve high living standards requires that a specialist somehow use the knowledge of other specialists." To become a cabinet maker, a carpenter must know that there exist woodworkers, nail makers, and toolmakers. But specialization does not beget further specialization through the aggregation of production knowledge alone. Ideas are also necessary. To decide to specialize, a carpenter must integrate his knowledge of how tools transform wood and nails into cabinets, his knowledge of existing specialists, and an understanding of what is useful and felicitous - and thus, profitable - about a world in which he produces more and perhaps ultimately finer cabinets.

Our data highlight the ways in which ideas limit how firm boundaries evolve. The

\footnotetext{
${ }^{3}$ We do not wish to imply that transaction costs do not hamper economic growth outside of our experiment; they surely do.
} 
current division of labor limits potential future divisions of labor when ideas to further specialize do not emerge. Ideas fuel economic growth. ${ }^{4}$ Adam Smith tells us that the greatest improvement in the powers of production are the effects of the division of labor. When today's division of labor does not constrain tomorrow's division of labor, the result is economic growth and prosperity.

\section{The Initial Environment}

Our economy consists of 4 agents, Teal, Green, Purple, and Brown, who interact across a series of discrete periods. In each period, every agent is endowed with $T=10$ seconds of production time $(t)$. Agents can use this production time on any of three actions: producing A units, producing $\bigcirc$ (circle) units, or producing $\$$ (cents).

Relative to the other three agents, Teal has unique production possibilities. Formally, Teal's production functions are:

$$
\mathbf{A}_{T}=\frac{3}{5} t_{\mathbf{A}}^{2} \quad \text { and } \quad \bigcirc_{T}=\frac{20}{37} t_{\mathrm{O}}
$$

Green, Purple, and Brown's production functions are:

$$
\mathbf{A}=\sqrt{2 t_{\mathbf{A}}} \quad \text { and } \quad \bigcirc=2 t_{\mathrm{O}}
$$

All agents share a common production function for $\$$ :

$$
\phi=\delta t_{\phi}
$$

where $\delta$ is a constant and $t_{\mathbf{A}}+t_{\mathrm{O}}+t_{\mathrm{\phi}} \leq T$.

\footnotetext{
${ }^{4}$ For a condensed discussion of such a thesis, see McCloskey (2006, 2010, 2016).
} 


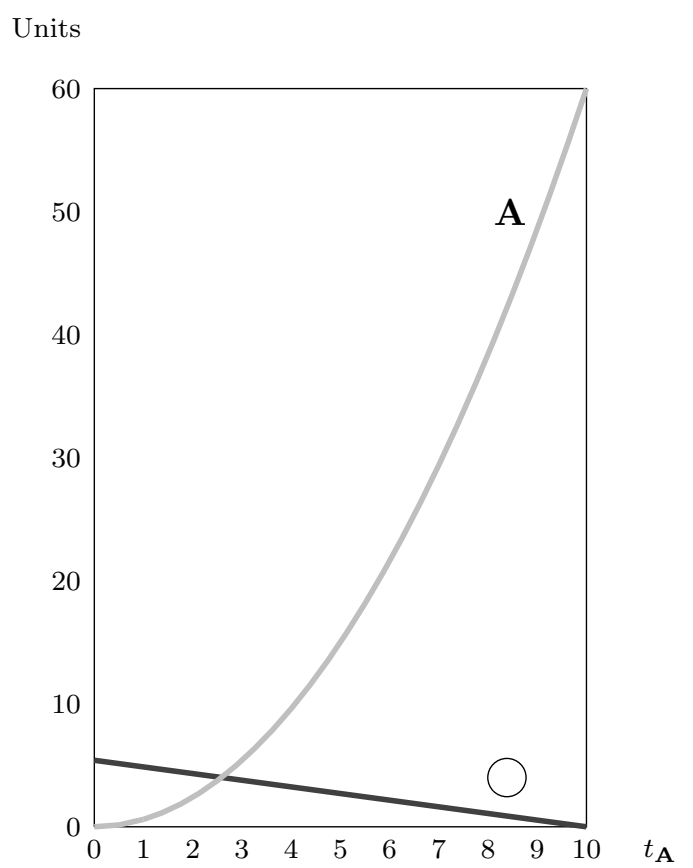

(a) Teal
Units

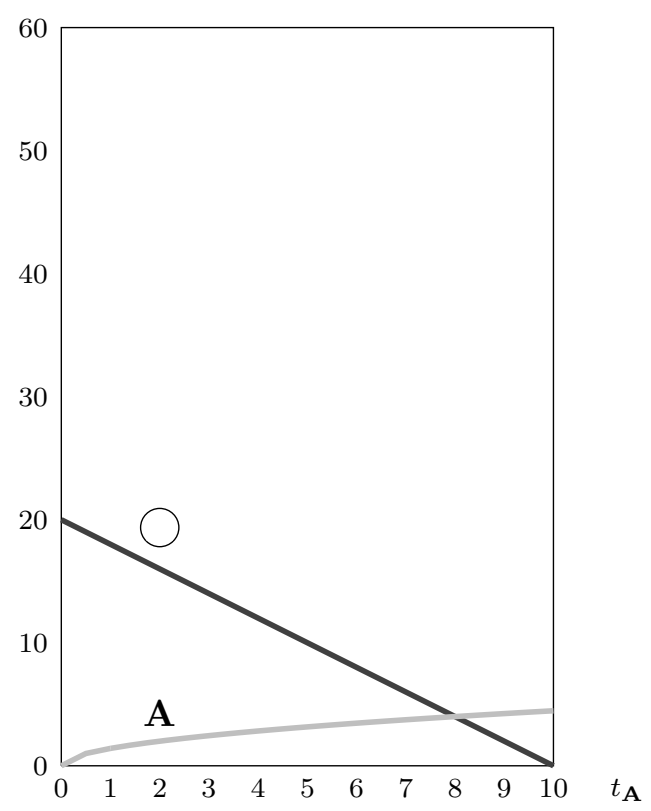

(b) Green/Purple/Brown

Figure 1: Production Functions Note: $t_{\mathrm{O}}=T-t_{\mathbf{A}}$

Figure 1 plots the agents' production functions. Teal possesses increasing returns to the production of As and constant returns to the production of $\bigcirc$ s. Green, Purple, and Brown have decreasing returns to the production of $\mathbf{A s}$ and constant returns to the production of $\bigcirc \mathrm{s}$.

In addition to As, $\bigcirc \mathrm{s}$, and $\phi$, agents can produce (A) ( "circle A's") according to the simple Leontief function:

$$
q^{(A)}=\min \{\mathbf{A}, \bigcirc\}
$$

Agents who do not specialize and produce both $\mathbf{A s}$ and $\bigcirc$ s can produce at most 4 (A) s each period given their 10 second time endowment.

If Teal specializes in the production of As by devoting all 10 seconds of production 
Average Cost

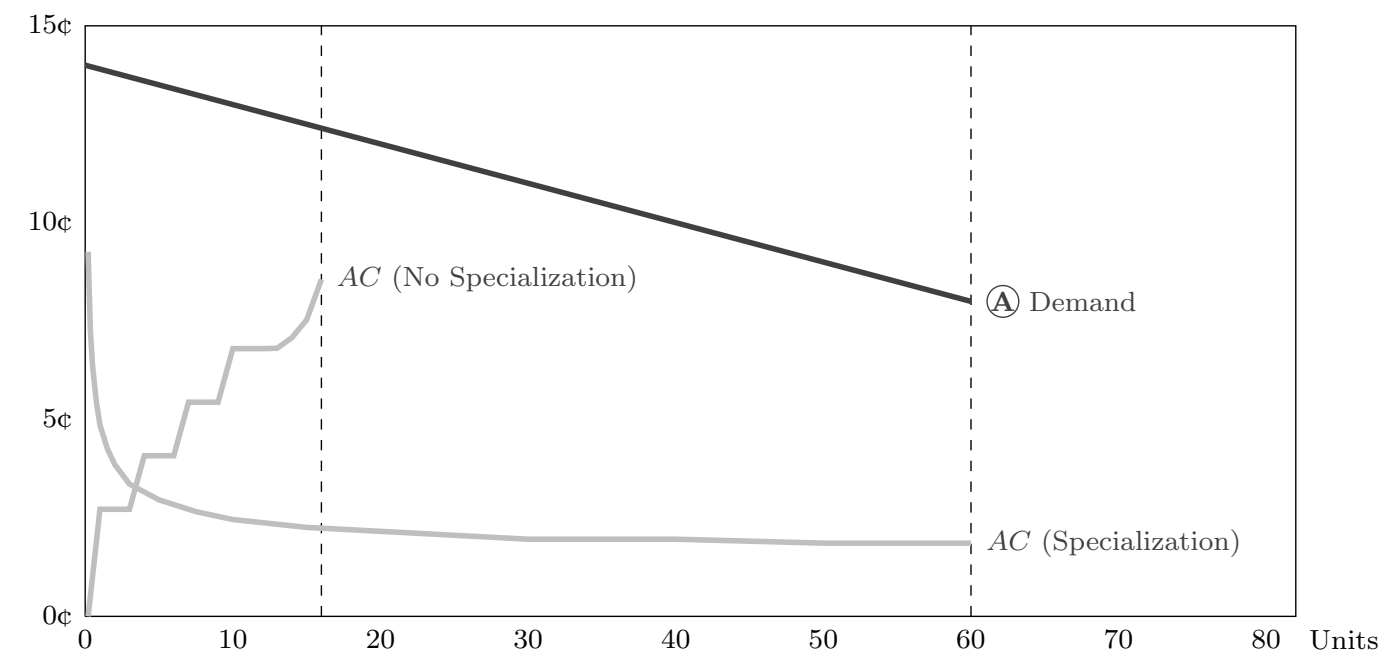

Figure 2: Gains from Specialization

time to As, she can produce 60 As. $^{5}$ Likewise, if Green, Purple, and Brown specialize in the production of $\bigcirc \mathrm{s}$, they each produce $20 \bigcirc \mathrm{s}$, for a total of $60 \bigcirc \mathrm{s}$. So absent a division of labor, the economy's maximum (A production is 16; with a division of labor, the maximum production is 60 (A)

Agents earn money in two ways: They can produce $\phi$ directly according to Equation (3) and they can sell (A) s to robot buyers. The demand for (A) consists of 60 buyers, each with a distinct reservation value between $8.0 \phi$ and $13.9 \phi$ in increments of $0.1 \phi$, which yields a discretized version of the following inverse demand function:

$$
P=14.0-0.1 Q^{\circledR}
$$

where $Q^{\circledR}$ denotes the total quantity of $($ s sold.

Figure 2 displays the gains from specialization. The two average cost curves are con-

\footnotetext{
${ }^{5}$ We use feminine pronouns for Teal and masculine pronouns for all other roles throughout the paper.
} 
structed by first deriving inverse production functions (time as a function of quantity) and total cost functions (using Equation (3) to monetize quantity in opportunity cost terms). With no specialization total market revenue is $198.4 \$(49.6 \oplus$ per seller $)$ and with complete specialization it is 480.0 \&, or 2.4 times higher than with no specialization.

\section{Experiment Details}

Prior to the start of the experimental session, 4 participants are randomly assigned to be Teal, Green, Purple, or Brown, and their respective roles remain fixed for the entire session. Figure 3 shows a bird's-eye screenshot of the experimental environment and a screenshot from a participant's perspective. During the session, participants move their avatar around the experimental environment by left-clicking on the spot in the environment they wish to move to. Participants are not aware of the total number of periods, but they know that each period has three phases: Production, Selling, and Chat, lasting 80 seconds, 30 seconds, and 20 seconds, respectively.

\section{$2.1 \quad$ Production}

As the name indicates, participants can only produce $\mathbf{A s}, \bigcirc$ s, or $\mathbb{\notin}$ during the Production phase. To convert production time into output, participants move their avatars across the environment until they are near a $\mathbf{A}, \bigcirc$, or $\$$ symbol. Right-clicking on the symbol causes a small box to appear, into which participants enter the amount of time they wish to devote to producing the desired object.

Objects are produced at a rate dependent on the participant's production function for the object in question. The large output symbols deliver 1 production time second's worth of output to the participants in every half second of real time. Participants who are relatively better at producing a particular object appear to produce that object more 
quickly than participants who are relatively worse at producing the same object. For example, because Teal enjoys increasing returns to the production of As, if Teal enters 5 seconds of production time for As, she produces $15 \mathrm{As}$ in 2.5 seconds of real time. If Purple, with decreasing returns to As, enters 5 second of time for $\mathbf{A s}$, he receives 3 As in 2.5 seconds.

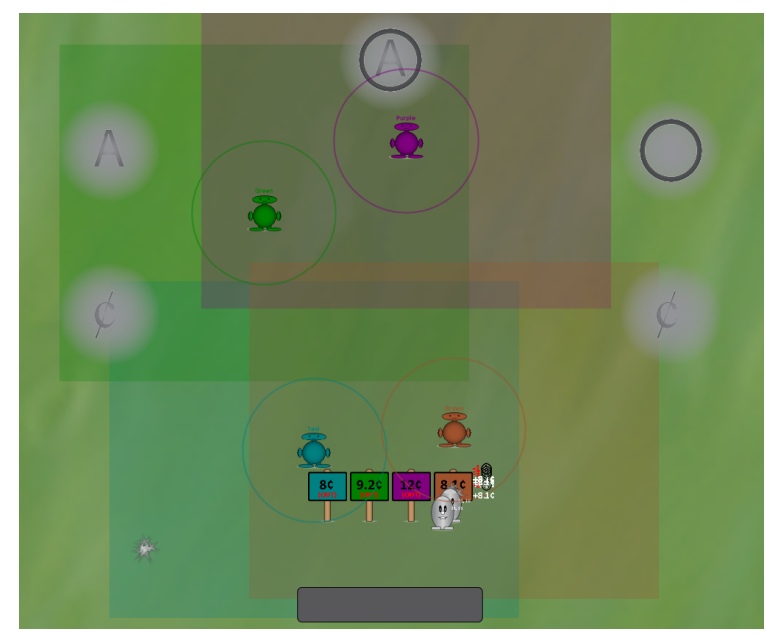

(a) Bird's-Eye Perspective

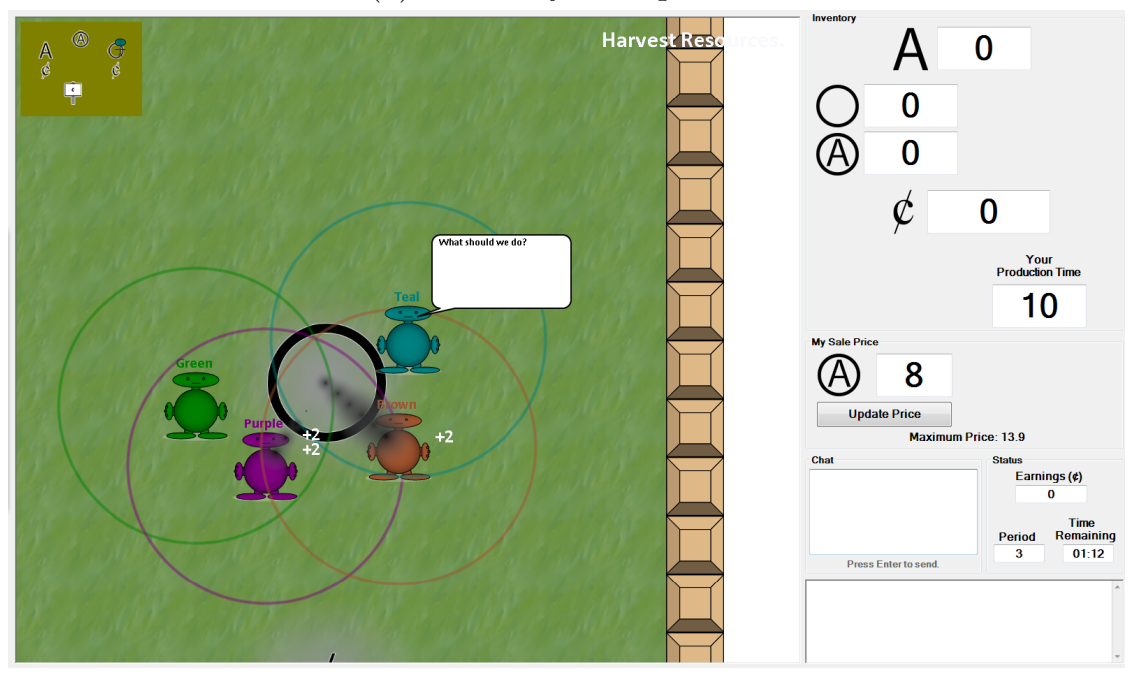

(b) Participant's Perspective

Figure 3: Experiment Screenshots 
Participants produce (A) $\mathrm{s}$ in the same manner as $\mathbf{A s}, \bigcirc_{\mathrm{s}}$, or $\mathbb{\mathcal { A }}$, except that when prompted by a pop-up box, they enter the number of $\mathbf{A s}$ and $\bigcirc \mathrm{s}$ they wish to devote to (A) production rather than entering production time. To produce (A) s, As and $\bigcirc$ s have to be entered in a 1:1 ratio per Equation (4). In addition to producing objects, participants can transfer As, $\bigcirc \mathrm{s}$, As, or $\notin$ to one another.

\subsection{Selling}

Each participant posts a selling price to a billboard during a period's Selling phase (see the bottom of Figure $3 \mathrm{~b})$. Buyers approach the billboards in random order, with their queue re-randomized each period. At any point during the Selling phase, participants can adjust their price to a tenth of a cent between $0.01 \mathrm{c}$ and $13.9 \mathrm{q}$. Participants accrue earnings in U.S. cents.

The buyers' demand for (A) is constant across all periods of the experiment. In each Selling phase of every period, the first buyer in the random queue approaches the A seller with the lowest billboard price. When two (or more) sellers share the lowest price, the buyer at the head of the queue randomly picks a seller to approach. Having approached a

seller, a buyer either buys 1 (A) from that seller if their reservation price exceeds the seller's posted price, or walks away if the seller's price exceeds their reservation price. If a buyer walks away, they issue a message that is visible to all sellers: "Your prices are too high." Buyers who walk away during a Selling phase do not attempt another (A) purchase during that Selling phase.

\subsection{Chat}

During all phases of each period, participants can type chat messages. These messages appear inside a chat bubble above the participant's avatar for a minimum of 5 seconds. 
Table 1: Summary of Treatments

\begin{tabular}{|c|c|c|c|c|c|c|c|c|c|}
\hline \multirow[b]{2}{*}{ Treatment } & \multirow[b]{2}{*}{ Sessions } & \multirow[b]{2}{*}{ Participants } & \multirow[b]{2}{*}{ Periods } & \multirow[b]{2}{*}{$\delta$-Value } & \multirow[b]{2}{*}{ Length } & \multicolumn{4}{|c|}{ Phase Length (sec) } \\
\hline & & & & & & Prod. & Sales & Chat & Break \\
\hline High Opportunity Cost & 6 & $24(4)$ & 36 & 0.0544 & $1: 45$ & 80 & 30 & 20 & 80 \\
\hline Low Opportunity Cost & 6 & $24(4)$ & 36 & 0.0272 & $1: 45$ & 80 & 25 & 15 & 70 \\
\hline External & 6 & $42(7)$ & 40 & 0.0272 & $2: 00$ & 80 & 25 & 15 & 70 \\
\hline Learning & 3 & $63(21)$ & 79 & 0.0272 & $4: 00$ & 80 & 25 & 15 & 70 \\
\hline Selection & 6 & $42(7)$ & 45 & 0.0272 & $2: 00$ & 80 & 25 & 15 & 70 \\
\hline \multirow[t]{2}{*}{ Accounting } & 6 & $66(11)$ & 50 & 0.0272 & $2: 00$ & 70 & 20 & 10 & 70 \\
\hline & 33 & 261 & & & & & & & \\
\hline
\end{tabular}

Note: Total participants per session given in parenthesis.

After 5 seconds, the bubble remains visible so long as the participant is stationary. Once a participant begins to move, the bubble disappears.

In addition to a short Chat phase at the end of each period, there is a lengthy chat Break following every fifth period. As Figures 3a and 3b illustrate, participants cannot see the entire experimental environment at once. Their view is restricted to roughly $9 \%$ of the total environment at any given time. For a participant, say Teal, to read a chat message from Brown, Brown has to be close enough to Teal to be visible within Teal's viewing window.

\subsection{Procedures and Related Literature}

Table 1 summarizes our six treatments. Our first two Opportunity Cost treatments only permit internal economies, while our final four allow for both internal and external economies. These latter treatments let us to examine very long session length (Learning), market selection (Selection), and detailed accounting information (Accounting). Each treatment is discussed in more detail below.

Our 261 participants were undergraduates at a private, liberal arts university in the United States with no prior experience in a similar environment. Participants were paid a show-up fee of $\$ 7.00$, and this amount was guaranteed regardless of their subsequent 
decisions in the experiment. Each session included roughly 15 minutes of self-paced instructions. The experimental instructions are reproduced in the Appendix in full.

Our experiment is related to Crockett, Smith, and Wilson (2009; hereafter CSW). In both our experiment and in CSW, specialization and exchange can generate wealth. In CSW, agents who specialize and exchange in pairs can achieve roughly three times more wealth relative to autarkic production. In this paper, agents who specialize and exchange in a quartet can generate nearly two and a half times more wealth relative to autarkic production.

Our experiment is more complex than CSW's experiment. In particular, there is no outside option in CSW; all production time must be allocated to producing either one or two consumption goods. Also, CSW participants have access to a table showing them how they have historically combined specific inputs into specific outputs. In our experiment an outside option is available to our participants, and they only learn what they can produce through experience and they must retain any knowledge they acquire about their production possibilities in memory.

Because both goods in CSW are consumption goods, their experimental design precludes an explicit price system. ${ }^{6}$ CSW pairs are like firms composed of two participants engaged in team production. ${ }^{7}$ Viewed this way, CSW pairs generate Marshallian internal economies, or, economies generated within a firm. ${ }^{8}$ In our experiment, team production, and thus internal economies, can occur among two, three, or four participants, with internal economies increasing in the team (firm) size. Moreover, while internal economies can be generated without an explicit price system in all of our experimental treatments as in CSW, four of our six experimental treatments allow for Marshallian external economies

\footnotetext{
${ }^{6}$ The use of a price system is the distinguishing mark of the firm for Coase (1937). A relative price is still possible in CSW, but there is no medium of exchange.

${ }^{7}$ Alchian and Demsetz (1972)'s three characteristics of team production are satisfied.

${ }^{8}$ See Marshall (1890), IV.IX.25.
} 
that can only be generated using explicit monetary transfers.

\section{Results}

We report our data treatment-by-treatment in the order in which they were conducted, except for the High Opportunity Cost and Low Opportunity Cost treatments, which were conducted simultaneously.

\subsection{The Opportunity Cost Treatments}

For convenience we use High and Low as shorthand treatment names. We conducted six High sessions and six Low sessions. The only difference between these two treatments is the value of $\delta$, the rate at which time can be converted to $\notin$. The parameter is set to 5.44 in High sessions and to 2.72 in Low sessions. This means that an agent devoting all 10 seconds of production time to $\Phi$, earns 54.4థ in High and 27.2థ in Low. Thus, the opportunity cost to producing $\mathbf{A s}$ or $\bigcirc \mathrm{s}$ is twice as great in the High sessions as in the Low sessions.

We first determine if there is a difference in market revenue across High and Low. Table 2 shows (A) market revenue for each High and Low session (averaged across all periods, and presented in per period terms). We report three different averages: (1) the mean for Teal alone, (2) the mean for Green, Purple, and Brown, and (3) the mean for all four agents. It is striking that while Low sessions all have average revenues of at least $\$ 0.80$ per period, High revenue averages above $\$ 0.80$ per period in three sessions, but below $\$ 0.25$ per period in three sessions.

It is instructive to see the evolution of market revenue in each session over time. Figure 4 shows the time series of (A) market revenue for each session. The data are presented as five-period moving averages, and are consistent with the averages presented in Table 
Table 2: Summary of Opportunity Treatments

\begin{tabular}{lccc}
\hline & \multicolumn{3}{c}{ A Mean Market Revenue (\$) } \\
\cline { 2 - 4 } Session & Teal & $\begin{array}{c}\text { Green/Purple/Brown } \\
\text { Average }\end{array}$ & Average \\
\hline High 1 & 0.96 & 0.88 & 0.90 \\
High 2 & 0.22 & 0.23 & 0.22 \\
High 3 & 0.20 & 0.24 & 0.23 \\
High 4 & 1.53 & 0.69 & 0.90 \\
High 5 & 0.08 & 0.07 & 0.07 \\
High 6 & 1.57 & 0.58 & 0.83 \\
& 0.76 & 0.45 & 0.53 \\
& & & \\
Low 1 & 1.84 & 0.66 & 0.96 \\
Low 2 & 0.78 & 0.84 & 0.82 \\
Low 3 & 1.13 & 0.79 & 0.87 \\
Low 4 & 0.92 & 0.83 & 0.86 \\
Low 5 & 1.22 & 0.77 & 0.89 \\
Low 6 & 0.98 & 0.92 & 0.93 \\
\cline { 2 - 4 } & 1.15 & 0.80 & 0.89 \\
\hline
\end{tabular}

Note: All figures are averages over all periods 1-36.

2. Using a robust rank order test (Feltovich, 2003), we reject a null hypothesis that the median of the distribution of mean (A) market revenues from High equals the median of the distribution of mean Low revenues $\left(U=1.549, n_{1}=n_{2}=6\right)$.

Clearly, revenue is greater in Low relative to High, but how exactly does the high opportunity cost reduce (A) market revenue? The following chat excerpt from High 5 illustrates. ${ }^{9}$ High 5 has the dubious distinction of having produced precisely zero As and s over the final 20 periods (see Figure 4). In what follows, references to "54" are to earning 54.4 from using all production time to produce $\$$. The excerpt begins in Period 19:

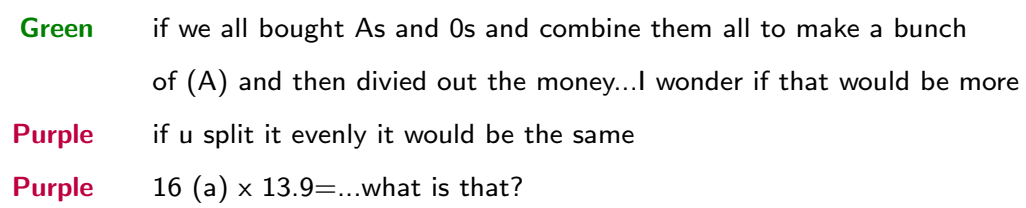

\footnotetext{
${ }^{9}$ The chat excerpts in this paper are lightly edited for brevity and clarity. Full chat transcripts are available from the authors.
} 


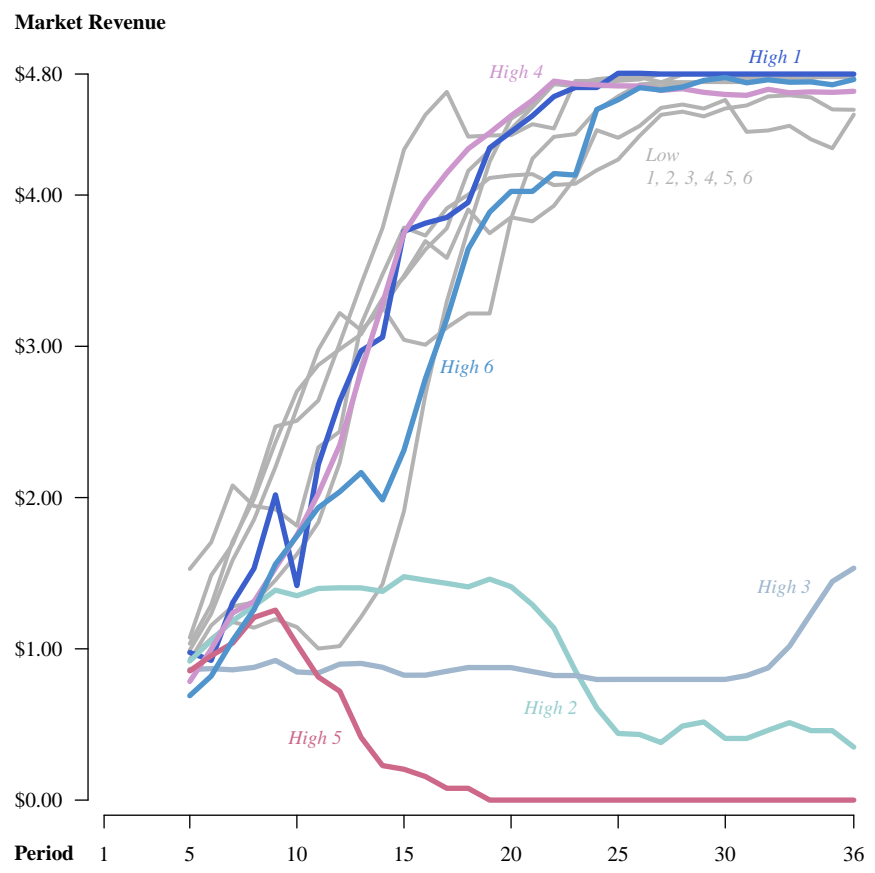

Figure 4: Opportunity sessions

Note: Time series are 5-period moving averages

Brown 222.4

Period 20

$\begin{aligned} \text { Green } & \text { lets try it next round } \\ \text { Green } & 2 \text { people buy all As } \\ \text { Green } & 2 \text { people buy all } 0 \text { s } \\ \text { Purple } & 222.4 / 4 \text { about } 55 \\ \text { Green } & \text { then one person will make the }(\mathrm{A}) \text { and sell it for like } 13 \\ \text { Green } & \text { and we'll see hjow much it is } \\ \text { Brown } & \text { yes } \\ \text { Purple } & \text { we already make } 54 \text { guarantee } \\ \text { Purple } & \text { u end up with about } 55 \text { each } \\ \text { Green } & \text { copy that, so i guess everything evens out } \\ \text { Teal } & \text { so we doing it or not? } \\ \text { Green } & \text { why not? } \\ \text { Purple } & \text { also no guarantee of buuying at } 13.9 \\ \text { Green } & \text { if its the same, lets try it }\end{aligned}$




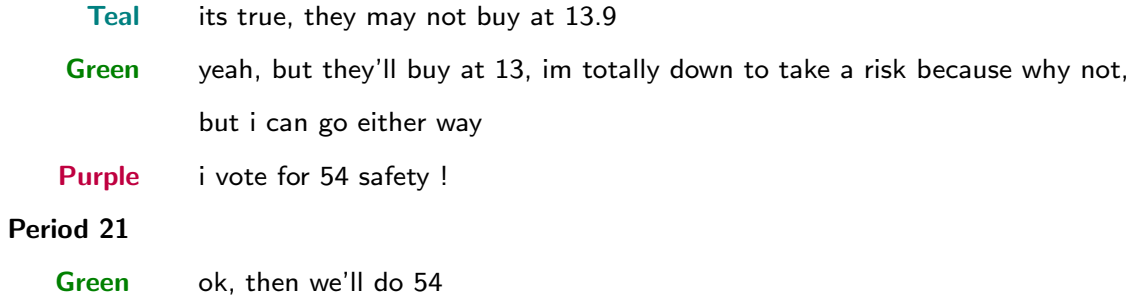

This discussion suggests that the "safety" of the high outside option hinders High 5 specialization. By frequently exercising their outside $\$$ option, High participants do not acquire as much production experience as do Low participants. As a consequence, they are less likely to realize the benefits of specialization than are Low participants. We conclude that low opportunity costs are sufficient for the emergence of internal economies in our new experimental platform.

We have demonstrated that when the opportunity cost to producing $\mathbf{A s}$ and $\bigcirc \mathrm{s}$ is low in our experiment, specialization occurs and that revenue is close to maximal. But according to growth theory, economic growth relies on Marshallian external economies, or, economies "dependent on the general development of the industry" (Marshall, 1890, IV.IX.25). ${ }^{10}$ We now report our External treatment that allows for potential external economies.

\subsection{The External Treatment}

To accommodate external economies, we made changes to our initial experimental environment. We begin this section by discussing how we change our Opportunity Cost environment into our External environment.

\footnotetext{
${ }^{10}$ See also Romer (1986), pp.1004-1005.
} 


\subsubsection{Changes to the Initial Environment}

Our six External sessions are 40 periods long with 7 participants who are randomly assigned the role of either Teal, Green, Purple, Brown, Pink, Gray, or Khaki. Teal's production functions in External are slightly altered versions of Equation (1):

$$
\mathbf{A}_{T}^{\prime}=1.2 t_{\mathbf{A}}^{2} \quad \text { and } \quad \bigcirc_{T}^{\prime}=0.5129 t_{\mathrm{O}}
$$

Green, Purple, and Brown's production functions are:

$$
\mathbf{A}^{\prime}=\sqrt{2 t_{\mathbf{A}}} \quad \text { and } \quad \bigcirc^{\prime}=2 t_{\mathrm{O}}
$$

The three new participants, Pink, Gray, and Khaki, have the following production functions:

$$
\mathbf{A}^{\prime}=\sqrt{2 t_{\mathbf{A}}} \text { and } \quad=2 t_{\mathbf{O}}
$$

Also, Pink, Gray, and Khaki can convert As and s into Red As by:

$$
\operatorname{Red} \mathbf{A}=\min \{\mathbf{A}, \mathbf{O}\}
$$

For all participants, the production function for cents is $\mathbb{C}=2.72 t$ as in the Low treatment.

As before, Teal possesses increasing return to As and constant returns to $\bigcirc \mathrm{s}$, and Green, Purple, and Brown have decreasing returns to the production of As and constant returns to the production of $\bigcirc \mathrm{s}$. The new participants, Pink, Gray, and Khaki, have decreasing returns to the production of As and constant returns to the production of $\mathrm{s}$. Teal, Green, Purple, and Brown cannot produce Red A, and Pink, Gray, and Khaki cannot 


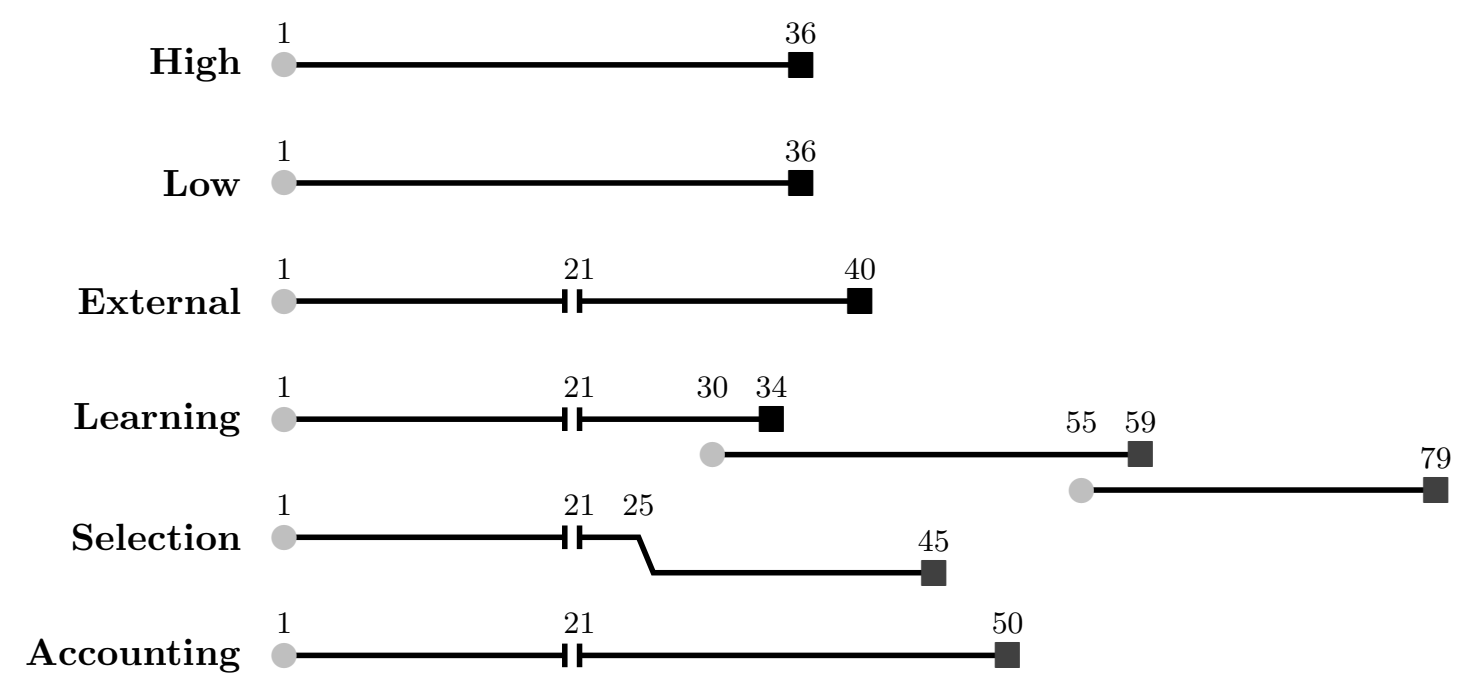

Figure 5: Treatment Timelines

produce (A. Finally, only Teal, Green, Purple, and Brown have (A price billboards and only Pink, Gray, and Khaki have Red A price billboards.

The (A) Market in External functions as in High and Low, and there is also a Red A Market which is identical to the (A) Market (60 buyers, random queue, etc.) except that automated buyers possess reservation prices for Red As as opposed to (A) s. The linear approximation to Red A Market demand is $P=14.0-0.1 Q^{\text {Red A }}$. Whereas the A Market is located at the very bottom of the experimental environment, the Red A Market is located at the very top. We refer to the (A) Market as the "Internal Market" and the Red A Market as the "External Market."

Figure 5 shows timelines for the different treatments in the experiment. In each timeline, lighter circles denote the first period of the treatment and darker squares represent the final period. For the first 20 periods of the External sessions, Teal, Purple, Green, Brown and the (A) Market are isolated from Pink, Gray, Khaki and the Red A Market by a wall through which participants cannot maneuver. 
Note from Equation (6) that External Teals can produce a maximum of 120 As. In aggregate, Green, Purple, and Brown can produce $60 \bigcirc$ s. Thus, despite Teal's improved production ability, 60 remains the maximum number of As (and there are still only 60 potential (A) buyers in External). As before, specialization in production generates 60 (A) s compared to 16 (A) s without specialization, and specialization can more than double Internal Market revenue.

During the first 20 periods of the External sessions, Pink, Gray, and Khaki cannot gain from specialization and exchange because they are all alike in their production capabilities. They can make at most 12 Red As, and their maximum Red A revenue is 153.6 p per period (38.4థ per participant, per period).

After the Selling phase in Period 20, but prior to Period 21, the wall separating the Internal and External Markets disappears. The line breaks in the timelines in Figure 5 indicate when the wall disappears to unite the two markets. With no wall present, all seven participants are free to roam the entire experimental environment. After Period 20, external economies are possible for the External Market.

If Teal devotes all 10 seconds of production time to As, she produces 120 As. Half of these can be exchanged for $\bigcirc$ s or sold for $\notin$ to Green, Purple, or Brown. The other half can be sold for $\$$ to Pink, Gray, or Khaki. Because Teal cannot sell Red As, her productive efficiency can only yield external economies for Pink, Gray, or Khaki via market transactions for cash-not like-kind exchanges of inputs.

Before reporting the External results, we define two metrics that we use throughout this Results section. First, let the Index of Specialization and Revenue Maximization (ISRM) be:

$$
I S R M=\frac{\text { Realized Revenue }- \text { Max Revenue (no specialization) }}{\text { Max Revenue (specialization) - Max Revenue (no specialization) }},
$$


where ISRM $\in[-0.7,1.0]$. If realized revenue is lower than the maximum revenue without specialization, $I S R M<0.00$. On the other hand, if realized revenue equals the maximum revenue without specialization, $I S R M=0.00$, and if it equals the maximum revenue with specialization, $I S R M=1.00$.

Our second metric splits up the total surplus of 480 क into different components. We report four components (or "splits") of surplus: realized revenue, lost revenue from mispricing, lost revenue from transaction costs, and unrealized external economies revenue. Let $\mathbf{R e d} \mathbf{A}^{*}$ denote the maximum number of $\mathbf{R e d}$ As possible:

$$
\boldsymbol{\operatorname { R e d }} \mathbf{A}^{*}=\min \left\{\left(\sum \mathbf{A}_{\text {int }}-\mathbf{A}\right)+\sum \mathbf{A}_{\text {ext }}, \quad \sum \mathbf{O}\right\}
$$

Also let $\mathbf{R e d} \mathbf{A}_{\text {sold }}$ denote the number of Red As actually sold, and $R_{\text {realized }}$ denote the realized revenue. Then:

Lost from mispricing $=\left(14.0-0.1 \mathbf{R e d} \mathbf{A}_{\text {sold }}\right) \mathbf{R e d} \mathbf{A}_{\text {sold }}-R_{\text {actual }}$,

Lost from trans. costs $=\left(14.0-0.1 \operatorname{Red} \mathbf{A}^{*}\right) \operatorname{Red} \mathbf{A}^{*}-\left(14.0-0.1 \operatorname{Red} \mathbf{A}_{\text {sold }}\right) \operatorname{Red} \mathbf{A}_{\text {sold }}$, Unrealized ext. economies $=480-\left(14.0-0.1 \operatorname{Red} \mathbf{A}^{*}\right) \mathbf{A}^{*}$.

If we add $R_{\text {realized }}$ to the sum of the three splits in Equation (12), we get 480 c.

The 'unrealized external economies revenue' component measures the extent to which external economies never emerge. This measure is positive whenever Teal has excess As that are not sold to Pink, Gray, or Khaki, or when As are available but Pink, Gray, or Khaki are not specializing in s, or when both these circumstances occur. 
Table 3: Summary of External Treatment

\begin{tabular}{|c|c|c|c|c|c|c|c|c|c|c|}
\hline \multirow[b]{2}{*}{ Session } & \multicolumn{4}{|c|}{ Mean Market Revenue (\$) } & \multicolumn{2}{|c|}{ ISRM } & \multicolumn{4}{|c|}{ Surplus Split } \\
\hline & Teal & $\begin{array}{c}G / P / B \\
\text { Average }\end{array}$ & $\begin{array}{l}\text { Internal } \\
\text { Average }\end{array}$ & $\begin{array}{l}\text { External } \\
\text { Average }\end{array}$ & $\begin{array}{l}\text { Internal } \\
\text { Market }\end{array}$ & $\begin{array}{c}\text { External } \\
\text { Market }\end{array}$ & $\begin{array}{l}\text { Real. } \\
\text { Rev. }\end{array}$ & $\begin{array}{l}\text { Price } \\
\text { Loss }\end{array}$ & $\begin{array}{l}\mathrm{TC} \\
\text { Loss }\end{array}$ & $\begin{array}{l}\text { Unreal. } \\
\text { EE Rev. }\end{array}$ \\
\hline External 1 & 0.91 & 0.59 & 0.67 & 0.46 & 0.49 & -0.01 & $31 \%$ & $1 \%$ & $0 \%$ & $68 \%$ \\
\hline External 2 & 1.12 & 0.80 & 0.88 & 0.59 & 0.89 & 0.36 & $56 \%$ & $5 \%$ & $3 \%$ & $35 \%$ \\
\hline External 3 & 3.06 & 0.20 & 0.92 & 0.53 & 0.87 & 0.19 & $45 \%$ & $5 \%$ & $8 \%$ & $42 \%$ \\
\hline External 4 & 1.52 & 0.56 & 0.80 & 0.37 & 0.71 & -0.07 & $27 \%$ & $2 \%$ & $1 \%$ & $70 \%$ \\
\hline External 5 & 2.68 & 0.47 & 1.02 & 0.65 & 0.89 & 0.42 & $60 \%$ & $8 \%$ & $10 \%$ & $21 \%$ \\
\hline \multirow[t]{2}{*}{ External 6} & 0.32 & 0.37 & 0.36 & 0.42 & -0.14 & -0.06 & $28 \%$ & $1 \%$ & $2 \%$ & $70 \%$ \\
\hline & 1.60 & 0.50 & 0.77 & 0.50 & 0.62 & 0.14 & $41 \%$ & $4 \%$ & $4 \%$ & $51 \%$ \\
\hline
\end{tabular}

Note: Revenue averages are for periods 1-40. ISRM and Surplus Split figures are averages over periods 21-40.

\subsubsection{Results}

Table 3 reports data on revenue, ISRM, and the surplus split. Its first four columns show mean market revenues, in per period terms and averaged across all periods. A new average is presented: the mean market revenue for the three agents in the External Market. The ISRM averages are taken over periods 21-40, and are shown for both the Internal and External markets. Finally, the last four columns of Table 3 contain information on the surplus split. These four components sum to $100 \%$ (because of rounding, they do not always sum precisely to $100 \%)$.

As with the Opportunity Cost data, we plot External revenue over time. Figure 6 shows the five-period moving average of market revenue for each session. External 2, 3, 4, and 5 clearly have higher average Internal Market revenue than External 1 and 6, although External 1 trends up over time. External 2, 3, and 5 also enjoy high External Market revenue, though external economies are never fully realized in any of the External sessions as indicated by the ISRM figures in Table 3.

Table 3 reveals that the unrealized external economies revenue exceeds the loss from either mispricing or transaction costs by a factor of ten. In other words, transaction costs only explain a small part of the failure of external economies in External. It is not the case 


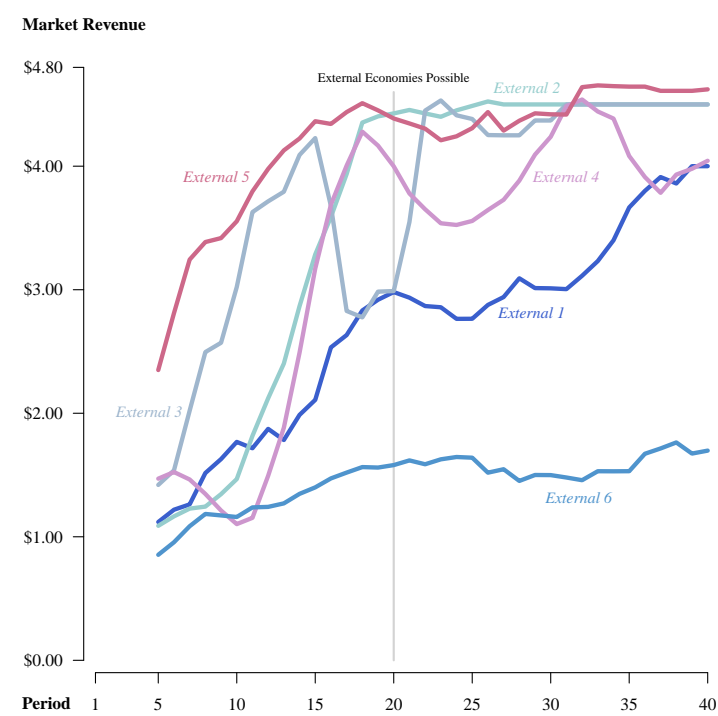

(a) Internal Market

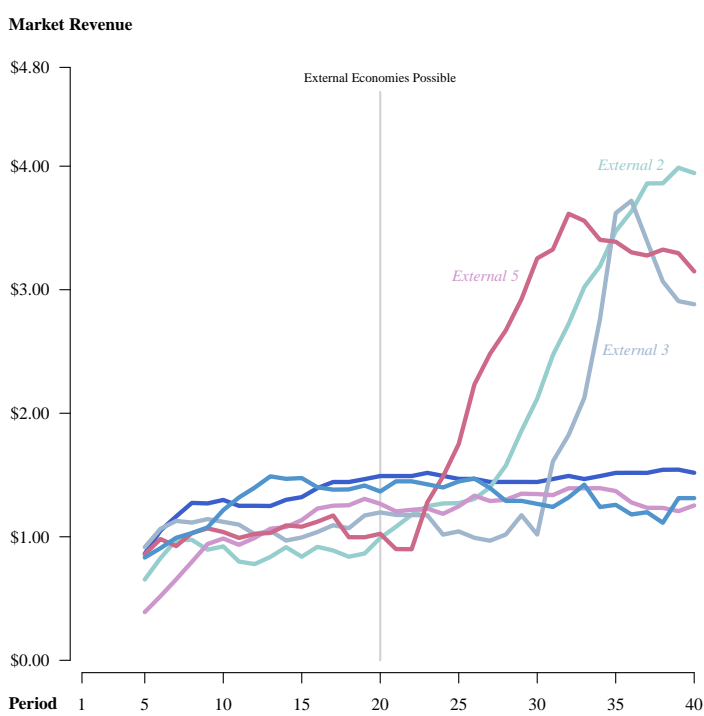

(b) External Market

Figure 6: External sessions

Note: Time series are 5-period moving averages

that Teal and Pink, Gray, and Khaki have trouble exchanging As for cents (which causes large revenue losses from transaction costs). Rather, Teal does not produce many excess As, and Pink, Gray, and Khaki do not specialize in s, or both.

A natural response to the fact that only half of our External sessions generate external economies is to suspect that External participants do not have adequate time to acquire the production knowledge necessary to develop the idea of specialization needed to generate external economies. To examine the effects of time and knowledge acquisition on external economies in our experiment, we now report results from our Learning treatment. 


\subsection{The Learning Treatment}

\subsubsection{Changes to the Initial Environment}

Our three Learning sessions last 79 periods and all involve 3 groups of 7 participants

each. For the first 29 periods, Learning is exactly like External. However, in Learning, participants are seated in visually isolated computer carrels with two seats at each computer screen. In Period 30, this message appears on each participant's screen:

The experiment will resume shortly after another person enters the lab, sits down next to you, and assumes control of the keyboard and mouse. This person will control the avatar, but you alone will receive all earnings.

Each participant is also instructed to give this new person next to them verbal instructions about the experiment. The new participants do not read the original instructions; their only knowledge of the experimental environment comes from the participants (Group I) preceding them in their randomly assigned roles. Once the new participants (Group II) enter the lab and assume control of the avatar, the experiment restarts. See Figure 5 for the Learning timeline.

Between periods 30 and 34, Group I trains Group II. During these periods, the seven members of Group II control the avatars, but earnings accrue to the seven members of Group I. Following Period 34, Group I exits the lab, and Group II then controls the avatar and accrues the earnings. From Period 55 through Period 59, this procedure is exactly repeated with Group III replacing Group II.

\subsubsection{Results}

Is more revenue per period generated in the longer Learning sessions relative to the shorter External sessions? Table 4 contains market revenue figures for the Learning treatment, broken up by session and group. While Internal Market revenue is high in all three sessions, 
Table 4: Summary of Learning Treatment

\begin{tabular}{|c|c|c|c|c|c|c|c|c|c|c|c|}
\hline \multirow[b]{2}{*}{ Session } & \multirow[b]{2}{*}{ Group } & \multicolumn{4}{|c|}{ (A) Mean Market Revenue (\$) } & \multicolumn{2}{|c|}{ ISRM } & \multicolumn{4}{|c|}{ Surplus Split } \\
\hline & & Teal & $\begin{array}{c}G / P / B \\
\text { Average }\end{array}$ & $\begin{array}{l}\text { Internal } \\
\text { Average }\end{array}$ & $\begin{array}{l}\text { External } \\
\text { Average }\end{array}$ & $\begin{array}{c}\text { Internal } \\
\text { Market }\end{array}$ & $\begin{array}{c}\text { External } \\
\text { Market }\end{array}$ & $\begin{array}{l}\text { Real. } \\
\text { Rev. }\end{array}$ & $\begin{array}{l}\text { Price } \\
\text { Loss }\end{array}$ & $\begin{array}{l}\mathrm{TC} \\
\text { Loss }\end{array}$ & $\begin{array}{l}\text { Unreal. } \\
\text { EE Rev. }\end{array}$ \\
\hline \multirow{3}{*}{ Learning 1} & I & 1.47 & 0.58 & 0.81 & 0.42 & 0.42 & -0.07 & $27 \%$ & $7 \%$ & $21 \%$ & $44 \%$ \\
\hline & II & 2.01 & 0.69 & 1.02 & 0.42 & 0.74 & -0.08 & $26 \%$ & $2 \%$ & $16 \%$ & $56 \%$ \\
\hline & III & 2.22 & 0.75 & 1.11 & 0.47 & 0.88 & -0.03 & $30 \%$ & $1 \%$ & $2 \%$ & $67 \%$ \\
\hline \multirow{3}{*}{ Learning 2} & I & 1.34 & 0.49 & 0.70 & 0.56 & 0.46 & 0.24 & $48 \%$ & $10 \%$ & $11 \%$ & $32 \%$ \\
\hline & II & 2.32 & 0.62 & 1.04 & 1.20 & 0.78 & 0.63 & $75 \%$ & $9 \%$ & $3 \%$ & $14 \%$ \\
\hline & III & 2.39 & 0.67 & 1.10 & 1.42 & 0.86 & 0.84 & $89 \%$ & $3 \%$ & $2 \%$ & $6 \%$ \\
\hline \multirow{4}{*}{ Learning 3} & I & 1.00 & 0.55 & 0.66 & 0.38 & 0.49 & -0.06 & $28 \%$ & $2 \%$ & $2 \%$ & $69 \%$ \\
\hline & II & 1.69 & 0.73 & 0.97 & 0.51 & 0.67 & 0.00 & $32 \%$ & $0 \%$ & $0 \%$ & $68 \%$ \\
\hline & III & 2.17 & 0.76 & 1.11 & 0.48 & 0.88 & -0.03 & $30 \%$ & $1 \%$ & $1 \%$ & $69 \%$ \\
\hline & & 1.84 & 0.65 & 0.95 & 0.65 & 0.69 & 0.16 & $43 \%$ & $4 \%$ & $6 \%$ & $47 \%$ \\
\hline
\end{tabular}

Note: ISRM calculated for periods 21-34 for Group I, periods 35-59 for Group II, and periods 60-79 for Group III.

External Market revenue varies across sessions and is largest in Learning 2. Figure 7 confirms that external economies are much greater in Learning 2 than Learning 1 or Learning 3. Note from Table 4 that average External Market ISRM is never positive in Learning 1 and Learning 3, but averages 0.84 in Group III in Learning 2.

None of the Learning sessions are alike. In Learning 1, Group I steadily decreases the unrealized external economies revenue (see Figure 8). However, during Group II's tenure, things quickly regress. Group III then fails to generate external economies throughout the rest of the session. This history is explained by a massive failure to communicate. While Teal's name is mentioned 122 times in Learning 1 during Group II's tenure (Periods 30-54), Teal herself types just 7 chat messages!

Unlike Learning 1, Learning 2 generates substantial external economies. Group I starts producing these economies, but when Group II enters the lab, they temporarily disappear because Teal produces zero As in Period 37. $60 \bigcirc$ s and $40 \bigcirc$ s are produced, but because no As are available, no revenue is earned. The unrealized external economies revenue spikes to $100 \%$ in Period 37, but Teal immediately returns to making 120 As in Period 


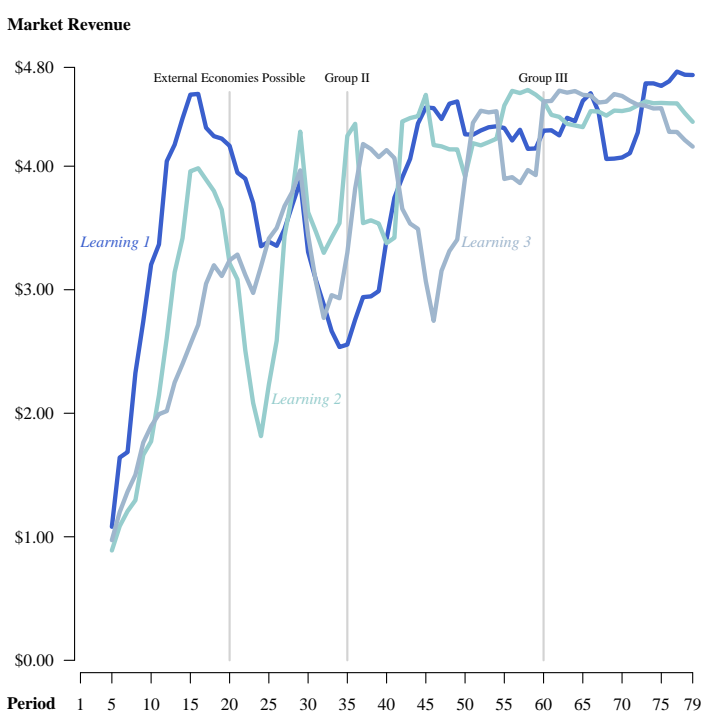

(a) Internal Market

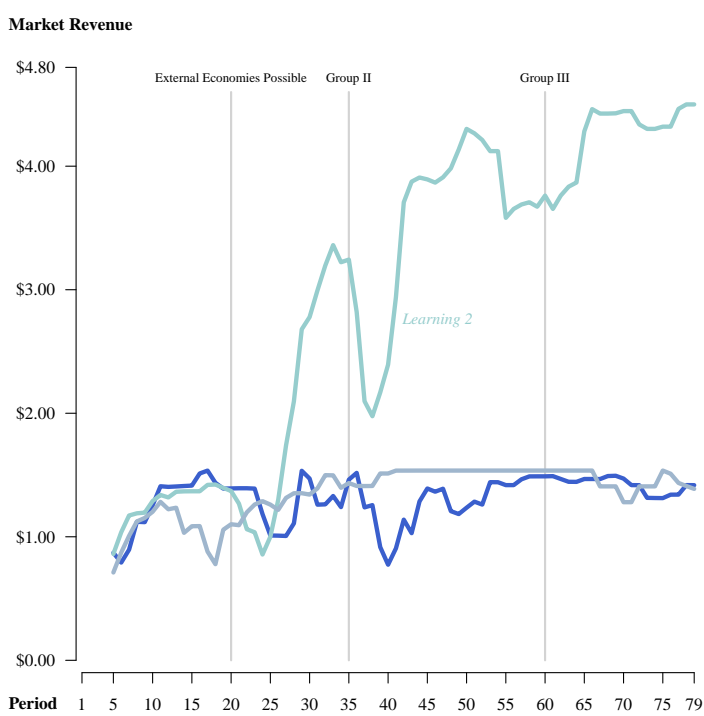

(b) External Market

Figure 7: Learning sessions

Note: Time series are 5-period moving averages

38. A second, smaller spike coincides with Group III's entrance, but unrealized external economies revenue averages just $6 \%$ during Group III's tenure.

Our final Learning session resembles Learning 1 more than Learning 2. As Figure 8 shows, the unrealized external economies revenue in Learning 3 is approximately $70 \%$ throughout the session. Remarkably, none of the three Teals in Learning 3 mention their ability to produce 60 or more As in a chat message. Moreover, in all 79 periods, these Teals never once produce 120 As.

Learning 2 suggests that session length can spur external economies, but the other two Learning sessions make it clear that simply increasing session length does not consistently produce external economies. The Learning sessions highlight Teal's importance in our experiment. Teal alone has increasing returns. Because we randomly select a participant for the Teal role in each session, Teal is more proficient in some sessions, but less so in 


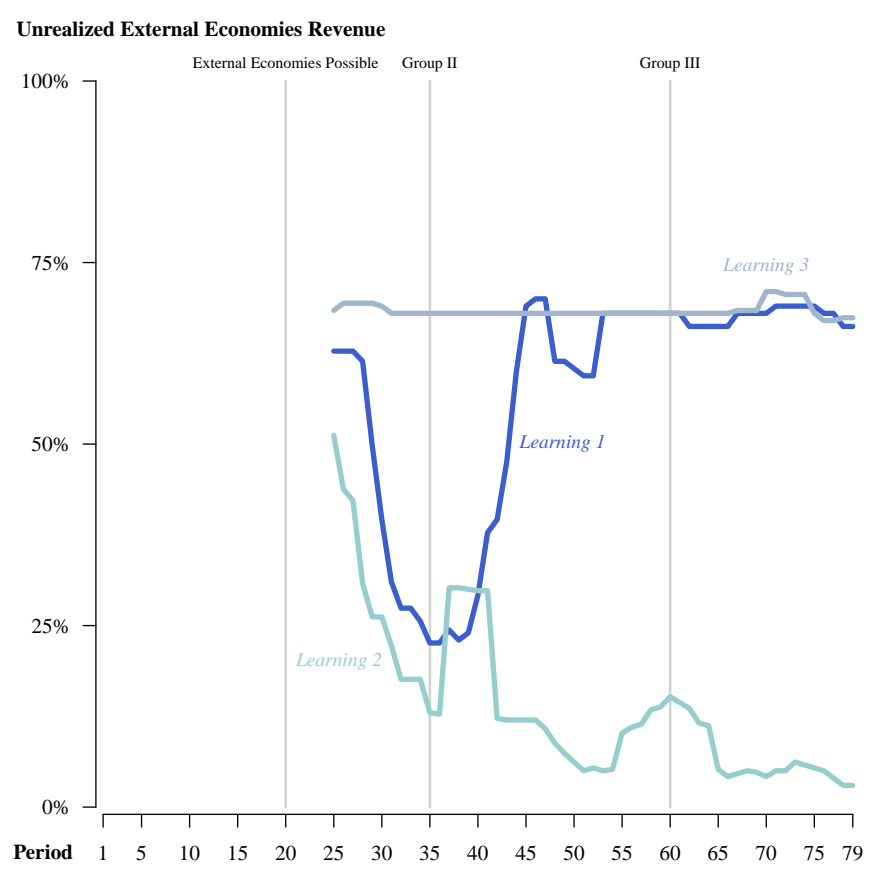

Figure 8: Unrealized External Economies Note: Times series are 5-period moving averages

others.

Outside of the economics laboratory, agents with increasing returns are likely to be more proficient than average or 'market selection' may result in more proficient agents acquiring increasing returns from less proficient agents. According to the market selection hypothesis: "Among all competitors, those whose particular conditions happen to be most appropriate of those offered to the economic system for testing and adoption will be 'selected' as survivors" (Alchian, 1950, pp.213-214). To examine the effect of market selection on external economies, we now report on our Selection treatment. 


\subsection{The Selection Treatment}

\subsubsection{Changes to the Environment}

The Selection timeline in Figure 5 shows that these sessions are equivalent to the External and Learning sessions through Period 24. Before Period 25, the experiment pauses and the participant with the highest average earnings during periods 15-24 (among Teal, Purple, Green, and Brown) sees the following message on their computer screen:

You now have the option to produce As and $\bigcirc$ s using the other people's allocations of production time. If you exercise this option, you will be the only person who can produce and sell (A).

In exchange for this capability, you will have to pay the other people a fixed amount of money each period. After the selling phase ends, the software will automatically transfer the following amounts from your earnings to the other people:

[The automatic transfer amounts are shown here.]

The automatic transfers are:

$$
\Phi_{i}=1.2\left(\frac{1}{10} \sum_{t=14}^{24} \pi_{t}^{i}\right)
$$

where $i$ denotes the agents who are "bought out" at a $70 \%$ premium above their past average earnings. ${ }^{11}$ If the highest earner declines the buyout offer, the same offer is presented, in turn, to the next highest earner until either a buyout is exercised, or all four agents pass on the offer. The experiment then continues for 20 periods and ends after Period $45 .{ }^{12}$

In addition to allowing for market selection, when the buyout option is exercised, this removes transaction costs associated with specialization and exchange in the Internal Mar-

\footnotetext{
${ }^{11}$ The fraction 1/10 in Equation (13) is not a typo. We intended the automatic transfers to be the average earnings from periods 14-24, which requires a coefficient of $1 / 11$. Because of a programming glitch, 1/10 was used. Because the participants are not told exactly how the automatic transfers are calculated, there is no issue for our results.

${ }^{12}$ In Selection, 1 production time second's worth of output is delivered to participants every quarter second.
} 
Table 5: Summary of Selection Treatment

\begin{tabular}{|c|c|c|c|c|c|c|c|c|c|c|c|}
\hline \multirow[b]{2}{*}{ Session } & \multirow[b]{2}{*}{$\begin{array}{c}\text { Buyout } \\
\text { Occurred }\end{array}$} & \multicolumn{4}{|c|}{ (A) Mean Market Revenue (\$) } & \multicolumn{2}{|c|}{ ISRM } & \multicolumn{4}{|c|}{ Surplus Split } \\
\hline & & Teal & $\begin{array}{c}G / P / B \\
\text { Average }\end{array}$ & $\begin{array}{l}\text { Internal } \\
\text { Average }\end{array}$ & $\begin{array}{l}\text { External } \\
\text { Average }\end{array}$ & $\begin{array}{l}\text { Internal } \\
\text { Market }\end{array}$ & $\begin{array}{c}\text { External } \\
\text { Market }\end{array}$ & $\begin{array}{l}\text { Real. } \\
\text { Rev. }\end{array}$ & $\begin{array}{l}\text { Price } \\
\text { Loss }\end{array}$ & $\begin{array}{l}\text { TC } \\
\text { Loss }\end{array}$ & $\begin{array}{l}\text { Unreal. } \\
\text { EE Rev. }\end{array}$ \\
\hline Selection 1 & Yes & 0.31 & 1.26 & 1.02 & 0.53 & 0.90 & 0.15 & $42 \%$ & $6 \%$ & $7 \%$ & $44 \%$ \\
\hline Selection 2 & Yes & 0.02 & 0.81 & 0.61 & 0.54 & 0.53 & 0.16 & $42 \%$ & $4 \%$ & $9 \%$ & $45 \%$ \\
\hline Selection 3 & & 0.48 & 0.40 & 0.42 & 0.35 & -0.08 & -0.07 & $27 \%$ & $1 \%$ & $2 \%$ & $71 \%$ \\
\hline Selection 4 & Yes & 0.27 & 0.62 & 0.53 & 0.81 & 0.20 & 0.60 & $73 \%$ & $4 \%$ & $2 \%$ & $22 \%$ \\
\hline Selection 5 & & 0.90 & 0.78 & 0.81 & 0.43 & 0.59 & -0.02 & $30 \%$ & $2 \%$ & $3 \%$ & $65 \%$ \\
\hline \multirow[t]{2}{*}{ Selection 6} & Yes & 0.23 & 0.79 & 0.65 & 0.36 & 0.54 & -0.09 & $25 \%$ & $4 \%$ & $2 \%$ & $68 \%$ \\
\hline & & 0.37 & 0.78 & 0.67 & 0.51 & 0.45 & 0.12 & $40 \%$ & $4 \%$ & $4 \%$ & $53 \%$ \\
\hline
\end{tabular}

Note: ISRM calculated for periods 21-45.

ket. The agent who acquires all of the Internal Market production capability can spend 10 seconds of "Teal time" on As and 30 seconds of "Green/Purple/Brown time" on $\bigcirc$ s, to quickly produce $60 \mathrm{As}$ and $60 \bigcirc$ s. Additionally, the three agents who are bought out are free to try to stimulate trade in surplus As between the "Acquirer" and the External Market.

\subsubsection{Results}

What effect, if any, does market selection have on revenue? Table 5 reports the market revenue, ISRM, and surplus split summary statistics for Selection. We compare revenue in External and Selection using four Wilcoxon rank-sum tests. Two of these tests (one for the Internal Market, one for the External market) compare revenue per period in periods 1-20 across External and Selection. The remaining two tests compare revenue per period in periods 21-40 across External and Selection. In all four tests, we find no significant difference in revenue (all $p>0.20$ ).

Table 5 shows that buyouts occur in four of the six Selection sessions. There is little evidence in the table to suggest that sessions with buyouts enjoy larger revenue than sessions without buyouts. Figure 9 shows average market revenue over time. For sessions with buyouts, the revenue time series is a dashed line post-buyout. Again, sessions with 


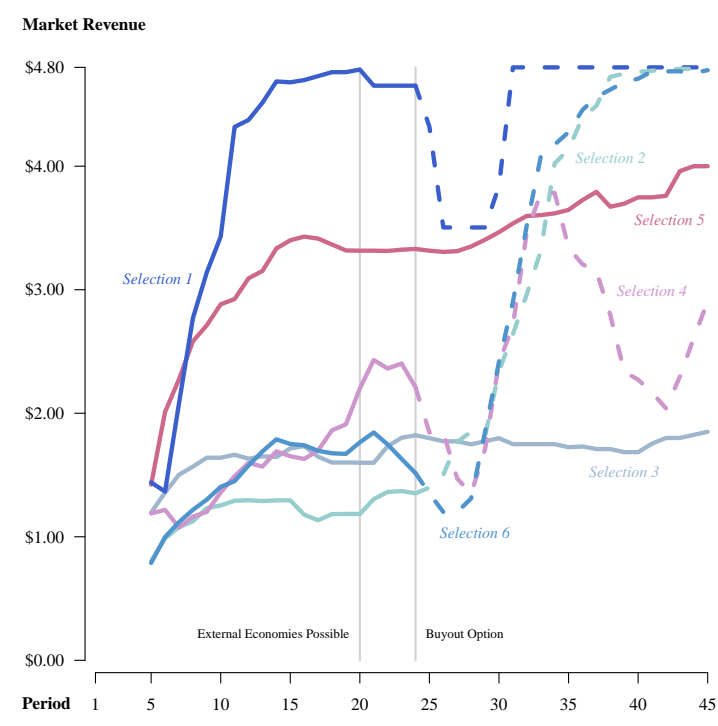

(a) Internal Market

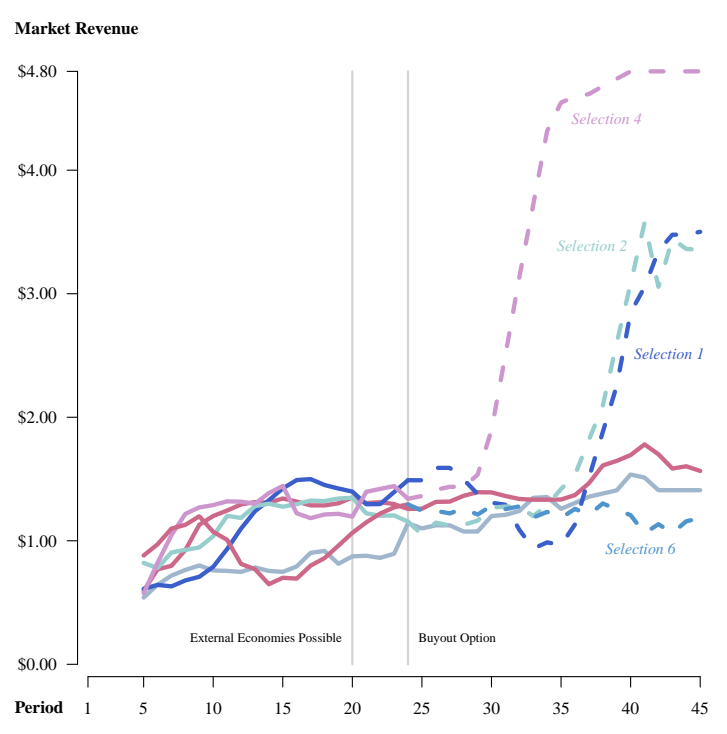

(b) External Market

Figure 9: Selection sessions

Note: The time series are 5-period moving averages

buyouts do not appear markedly more prosperous than those without buyouts. For example, Selection 1 is the wealthiest session prior to Period 24 and has a buyout. But the second wealthiest session (Selection 5) does not have a buyout, while the poorest session (Selection 2) does have a buyout.

Table 6 contains additional information on the buyouts. Production knowledge is essential for agents contemplating a buyout offer. Teal is in the best position to know how many As can be produced, yet Teal is presented with a buyout offer in four sessions and passes each time. It is also surprising that Selection 1 is the only session in which the first agent who is offered the buyout opportunity accepts it. The Selection 1 buyout decision seems straightforward, but the decisions in the other sessions do not.

In both Selection 3 and Selection 6, Teal does not realize the full possibilities of $\mathbf{A}$ production because the most As produced in any one period before the buyout decision 
Table 6: The Buyout Decision

\begin{tabular}{lcccccc}
\hline & Buyout & & & \multicolumn{2}{c}{ A Production } \\
\cline { 5 - 6 } Session & Occurred & Acquirer & Passes & Mean & Max \\
\hline Selection 1 & Yes & Green & 0 & 97 & 125 \\
Selection 2 & Yes & Purple & 2 & 30 & 83 \\
Selection 3 & & & 4 & 15 & 23 \\
Selection 4 & Yes & Green & 3 & 26 & 81 \\
Selection 5 & & & 4 & 43 & 127 \\
Selection 6 & Yes & Brown & 2 & 15 & 24 \\
\hline
\end{tabular}

Note: The production figures are from periods 1-24.

are $23 \mathrm{As}$ and $24 \mathrm{As}$, respectively. Similarly in Selection 4, 60 or more As are produced only once during periods 1-24. Curiously, Selection 5's Teal produces 120 As during one period (127 are produced in total), and $43 \mathrm{As}$ are produced on average before the buyout, yet no buyout occurs in Selection 5.

The "buyout bill," or the amount prospective buyers have to pay each period to acquire all of the Internal Market production capability, also fails to explain why buyouts are exercised. In Selection 2, Brown and Green both decline buyout offers that would make them liable for $29 \%$ of Internal Market total surplus, while Purple accepts an offer that commits him to send $30 \%$ of total surplus to his fellow participants each period. But in Selection 3, everyone passes on bills of between $35 \%$ and $39 \%$, and in Selection 1, Green accepts a buyout offer that commits him to send $86 \%$ of total surplus to his fellow participants.

The preceding paragraphs illustrate the difficulty of rationalizing the buyout decisions in Selection. Figure 9 and the ISRM numbers in Table 5 indicate that external economies are not generated in the two sessions without buyouts (Selection 3 and Selection 6). On the other hand, the buyout appears to promote external economies in Selection 4. In Selection 4, Green exercises a buyout offer after the other three participants all decline 
similar offers. After making just 12 As in Period 25, Green makes 120 As in Period 26. This chat sequence follows:

\begin{tabular}{|c|c|}
\hline Green & just got $120 \mathrm{~A}$ \\
\hline Pink & give some \\
\hline Gray & pass then around \\
\hline \multicolumn{2}{|l|}{ Period 27} \\
\hline Gray & $\begin{array}{l}\text { can i get some black a? } \\
\text { [Green gives Gray } \mathbf{6 0} \mathrm{As}_{\mathrm{s}}\end{array}$ \\
\hline Gray & thanks \\
\hline Pink & can i have black a? \\
\hline Green & next round pink \\
\hline Pink & okay thanks \\
\hline Green & will give 60 each round \\
\hline
\end{tabular}

Period 28

\section{[Green gives Pink $60 \mathrm{As}$ ]}

Khaki hook me up with some black $A$ please!

Green khaki you need any A?

Khaki YES PKEASE!

Khaki Thank you!

Period 29

Pink can i have some a please

Gray black a?

[Green gives Khaki $60 \mathrm{As}$ ]

Khaki Thank you

Pink a?

Green okay after this round i will give 20 a to gray, khaki, and pink

Green per round

Period 30

[Green gives Pink, Gray, and Khaki 20 As each]

Pink thanks green

Khaki Let me know if we can do anything for you green!

Gray thanks

Green anybody wanna shoot me some cents?

[Green receives $10 థ$ from Gray and $20 థ$ from Khaki] 
In Selection 4, the percent of unrealized external economies revenue averages $68 \%$ in periods 21-24. It stays at this level when Green first takes over all Internal Market production, but falls to $12 \%$ in Period 29, and is $0 \%$ from Period 30 until the end of the session. From Period 36 on, A revenue is maxed out at 480 .

Market selection also spurs external economies in Selection 1. In Period 28, Green says to Teal, Purple, and Brown: "go talk to the other team and figure out a way for us to trade please." In Period 30, Green reiterates: "tell them we trade our A for cents." The Internal Marketers finally teach Pink, Gray, and Khaki how to specialize in Period 42:

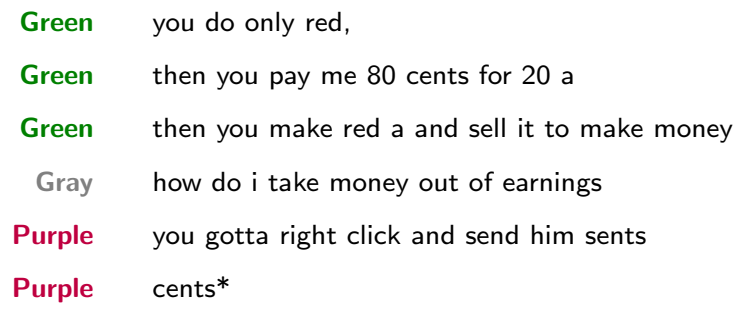

These success stories aside, our exogenous market selection mechanism does not consistently promote external economies. A common theme across our External, Learning, and Selection sessions is that external economies are slow to develop - or do not developbecause participants either do not know that Teal has increasing returns, or no one, including Teal, is alert to the idea of selling As to the External Market. Because limited supply and demand knowledge is a common theme across treatments, we now report our final treatment, Accounting, where each Internal Market participant has an adviser who receives detailed accounting information.

\subsection{The Accounting Treatment}

\subsubsection{Changes to the Initial Environment}

We conducted six Accounting sessions. As the timelines in Figure 5 show, these sessions are equivalent to our External sessions, but with 10 extra periods, for a total of 50 periods. 

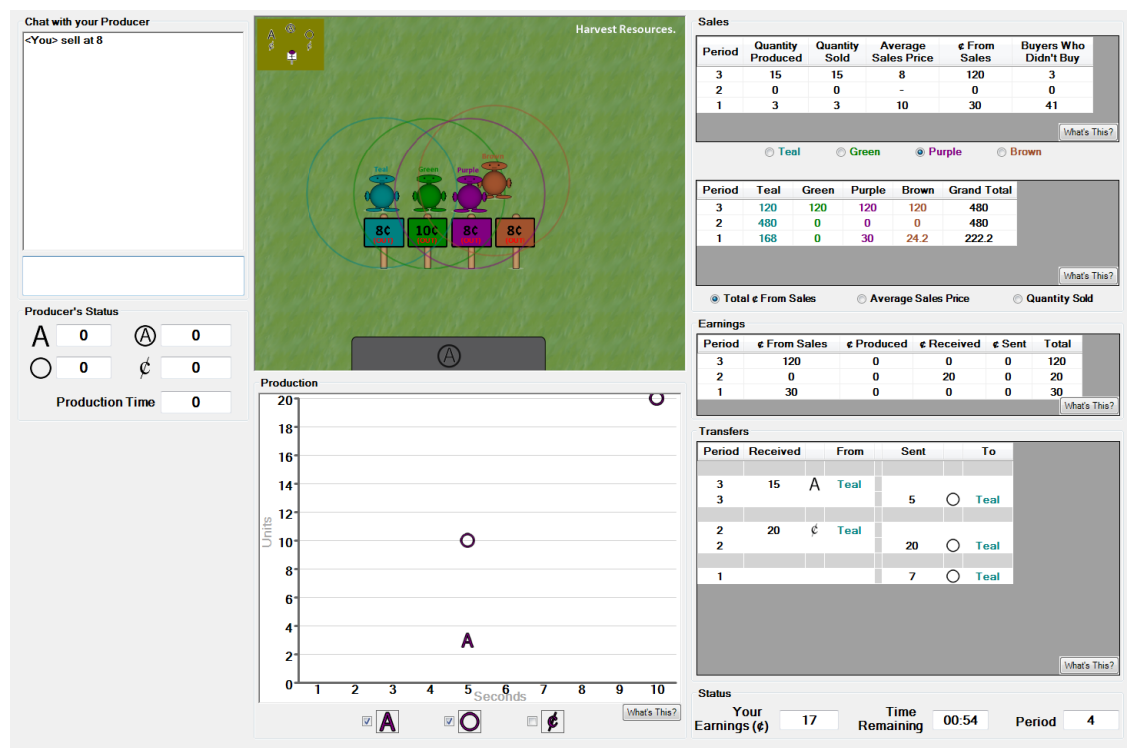

Figure 10: Accounting Screenshot

To ensure that these sessions finish in two hours, the experimental phases are shortened slightly (see Table 1). There are four new participants called "Advisers" in Accounting, increasing the total number of participants per session to 11, and we add the following line to the instructions for Teal, Green, Purple, and Brown:

In this experiment there are two types of people: producers and advisers. You are a producer. Each adviser reviews data to advise one and only one producer.

The 4 advisers complete the same instructions as the other 7 participants, after which they see the following message on their computer screen:

Your sole task is to review the data from the experiment and advise your producer. Your producer's total earnings will be split each period with you: $50 \%$ for the producer and $50 \%$ for you. You may chat with your producer throughout the experiment using the chat box in the upper left portion of the screen.

Thus, Teal's adviser receives half of Teal's earnings. The advisers are able to view a large 
Table 7: Summary of Accounting Treatment

\begin{tabular}{|c|c|c|c|c|c|c|c|c|c|c|}
\hline \multirow[b]{2}{*}{ Session } & \multicolumn{4}{|c|}{ (A) Mean Market Revenue (\$) } & \multicolumn{2}{|c|}{ ISRM } & \multicolumn{4}{|c|}{ Surplus Split } \\
\hline & Teal & $\begin{array}{c}G / P / B \\
\text { Average }\end{array}$ & $\begin{array}{l}\text { Internal } \\
\text { Average }\end{array}$ & $\begin{array}{l}\text { External } \\
\text { Average }\end{array}$ & $\begin{array}{l}\text { Internal } \\
\text { Market }\end{array}$ & $\begin{array}{c}\text { External } \\
\text { Market }\end{array}$ & $\begin{array}{l}\text { Real. } \\
\text { Rev. }\end{array}$ & $\begin{array}{l}\text { Price } \\
\text { Loss }\end{array}$ & $\begin{array}{l}\mathrm{TC} \\
\text { Loss }\end{array}$ & $\begin{array}{l}\text { Unreal. } \\
\text { EE Rev. }\end{array}$ \\
\hline Accounting 1 & 1.26 & 0.58 & 0.75 & 0.82 & 0.68 & 0.56 & $70 \%$ & $7 \%$ & $5 \%$ & $18 \%$ \\
\hline Accounting 2 & 1.20 & 0.59 & 0.74 & 0.44 & 0.49 & -0.01 & $31 \%$ & $0 \%$ & $0 \%$ & $68 \%$ \\
\hline Accounting 3 & 1.10 & 0.53 & 0.67 & 0.54 & 0.52 & 0.21 & $46 \%$ & $4 \%$ & $4 \%$ & $45 \%$ \\
\hline Accounting 4 & 0.94 & 0.47 & 0.59 & 0.49 & 0.35 & 0.07 & $36 \%$ & $4 \%$ & $8 \%$ & $52 \%$ \\
\hline Accounting 5 & 1.15 & 0.78 & 0.88 & 0.74 & 0.76 & 0.49 & $65 \%$ & $3 \%$ & $14 \%$ & $18 \%$ \\
\hline \multirow[t]{2}{*}{ Accounting 6} & 1.42 & 0.49 & 0.72 & 0.55 & 0.60 & 0.20 & $46 \%$ & $5 \%$ & $2 \%$ & $47 \%$ \\
\hline & 1.18 & 0.57 & 0.72 & 0.60 & 0.56 & 0.26 & $49 \%$ & $4 \%$ & $6 \%$ & $41 \%$ \\
\hline
\end{tabular}

Note: ISRM calculated for periods 21-50.

amount of data, including: quantities produced and sold, average market prices, market revenues, the number of buyers in the market who do not buy, and the number of cents produced, received, and sent by each Internal Market agent. They also see a graph that displays As, $\bigcirc$ s, and $\$$ on time. By mousing over data points in the graph, advisers can see precisely how long it takes their partner to produce certain items. Importantly, they do not see External Market data. Figure 10 is a screenshot of the adviser's screen.

\subsubsection{Results}

Do advisers with detailed accounting information increase realized revenue? Table 7 reports the revenue, ISRM, and surplus split summary statistics for Accounting, and Figure 11 shows each Accounting session's revenue time series. In all but one Accounting session, the External Market generates appreciable revenue by Period 50. Unfortunately, because External sessions last 40 periods, and Selection sessions last 45 periods, we cannot be certain that the external economies generated in Accounting in Periods 41-50 are due to treatment and not simply to the additional periods.

In Figure 11, Accounting 2 is the clear outlier session. The difference between this session and the other five Accounting sessions is stark. Note in Table 7 that ISRM is 


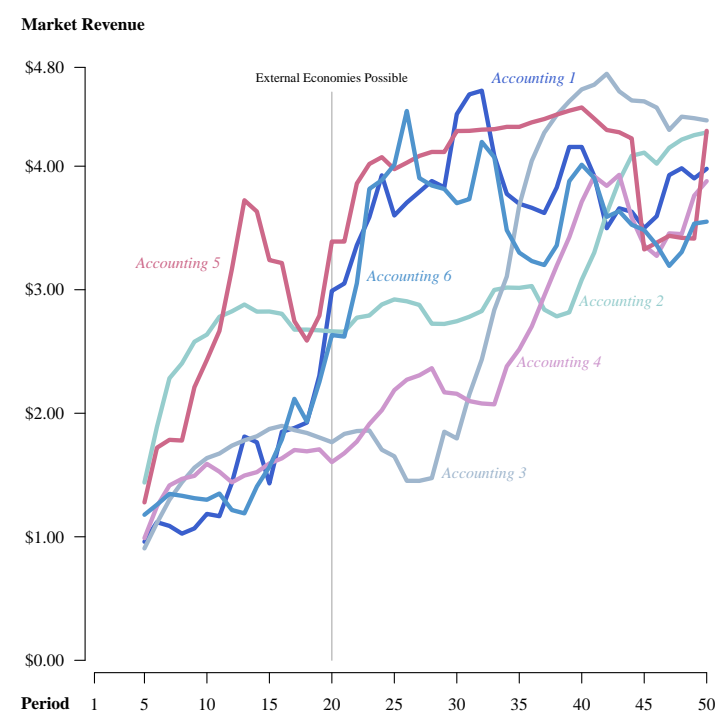

(a) Internal Market

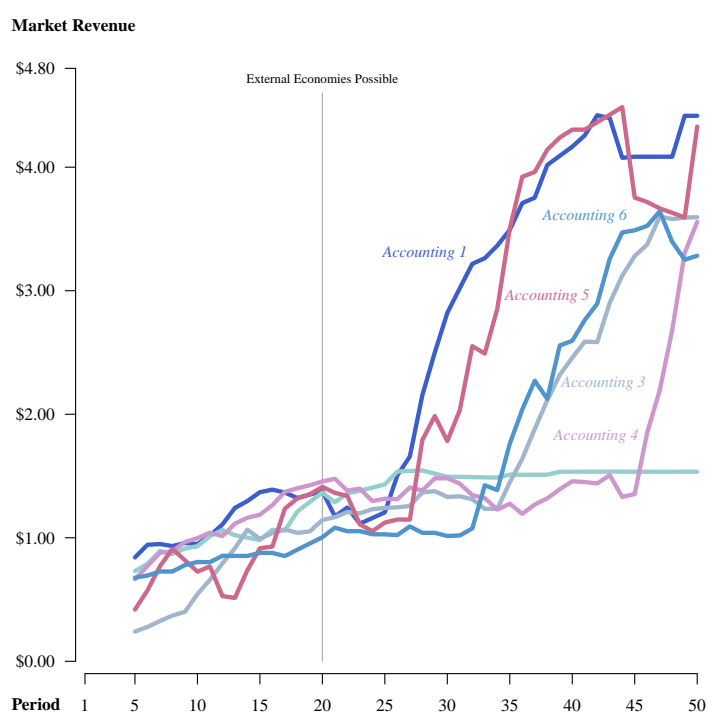

(b) External Market

Figure 11: Accounting sessions

Note: The time series are 5-period moving averages

essentially zero in the External Market and unrealized external economies revenue is high. The lack of specialization in Accounting 2's External Market means that Pink, Gray, and Khaki earn, on average, just $\$ 0.44$ each period.

Accounting 2 participants communicate frequently; in fact, they type the second-most messages among all Accounting sessions. But their communication is ineffective. After the wall disappears in Period 20, there are some tentative messages between the Internal and External Markets. For example, in Period 28, Khaki asks the Internal Marketers how many (A) s they sell. When Teal replies "10," Khaki asks, "HOW," but receives no answer. Khaki later reports this sales figure to Gray, who responds: "ugh they are making over double what we make!! not fair!"

In Period 31, the following discussion occurs in the External Market:

$$
\begin{aligned}
& \text { Gray they have really intense communication about production goin on down there } \\
& \text { Pink lol }
\end{aligned}
$$




$\begin{array}{ll}\text { Khaki } & \text { Iol and then theres us } \\ \text { Gray } & \text { they send stuff to each other } \\ \text { Khaki why } & \text { oh well } \\ \text { Khaki } & \text { too much effort } \\ \text { Graki } & \text { i dont understand what they do }\end{array}$

Notably, there is no mention of Teal's ability to produce 60 (or more) As in Accounting 2. By contrast, this ability is discussed 12 and 9 times in Accounting 1 and Accounting 5, respectively. Those sessions both enjoy very low unrealized external economies revenues (18\%, on average, in both sessions).

The following sequence of messages between Teal and Teal's adviser in periods 25-30 of Accounting 3 illustrate the value of advisers:

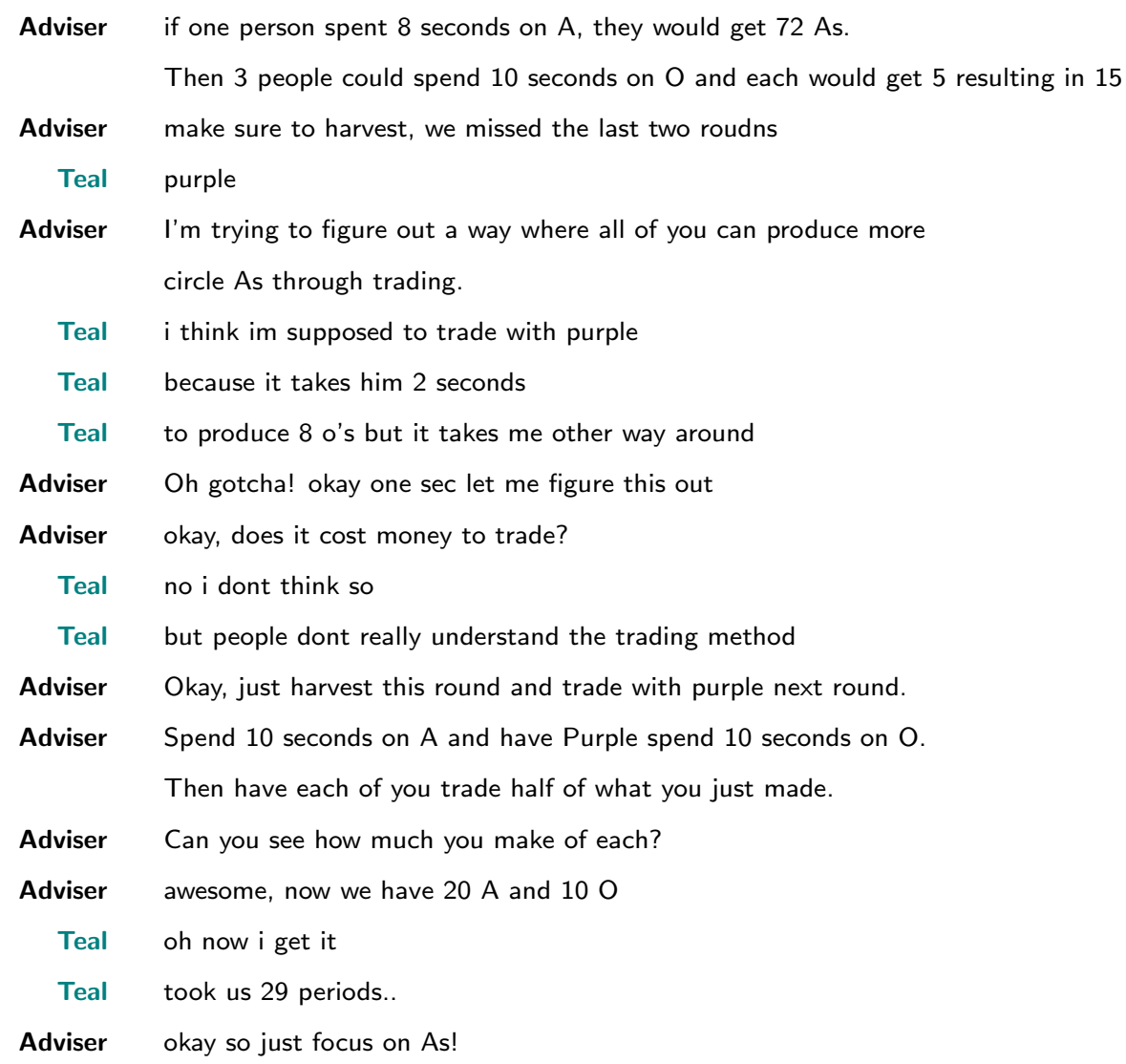




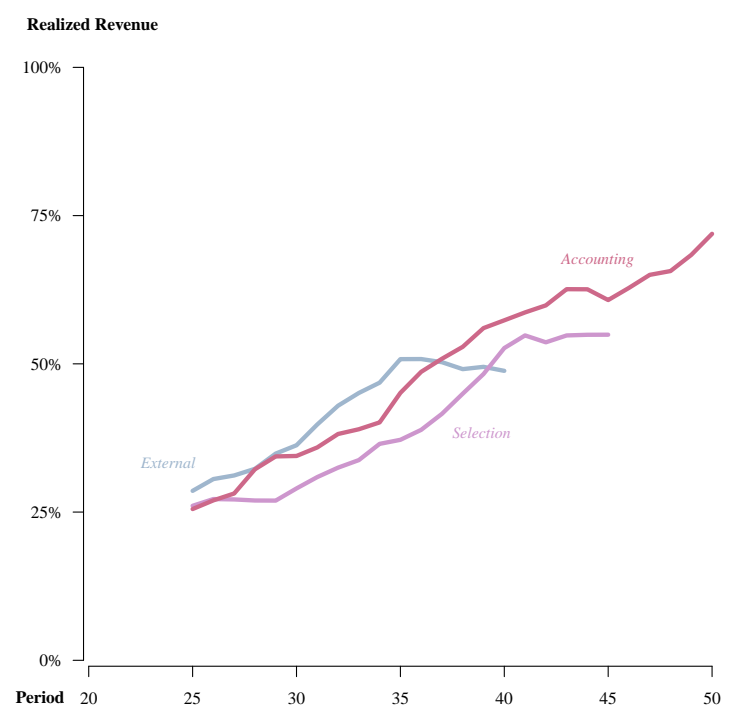

(a) Realized Revenue

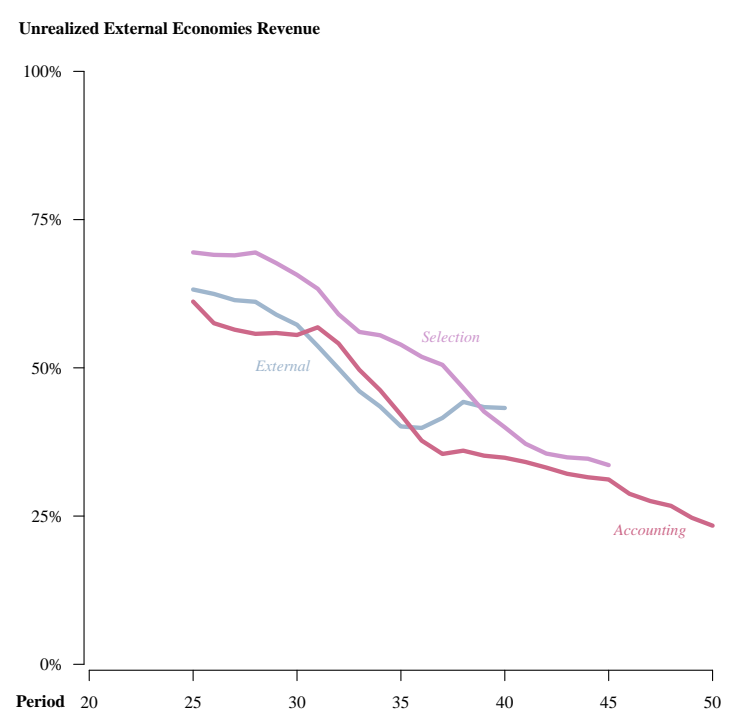

(b) Unrealized Ext. Economies

Figure 12: Surplus Split Comparisons

Note: The time series are 5-period moving averages

Can we quantify the value of Accounting advisers? Accounting is our only treatment in which the average revenue gain exceeds the average unrealized external economies revenues (see Table 7). Figure 12 shows the time series of revenue gain and of external economies revenue loss. The moving average of revenue gain in Accounting is always above that of revenue gain in Selection. Likewise, the unrealized external economies revenues are always less in Accounting relative to Selection. The moving averages for External track those of Accounting until Period 35, when External 3 and External 5 drag down External's overall average (see Figure 6).

The moving averages in Figure 12 suggest that Accounting advisers affect small improvements in awareness of production possibilities. However, the session variance is such that formal significance tests do not indicate differences across treatments. ${ }^{13}$ Thus we

\footnotetext{
${ }^{13}$ We find no statistical difference in average Internal Market revenue in periods 1-20 or periods 21-40, across External and Accounting, nor do we find differences across Selection and Accounting. Similarly, there is no difference in average External Market revenue in periods 1-20 or periods 21-40, either across External
} 
conclude that detailed accounting information has a small, positive - though statistically insignificant - impact on external economies.

\section{Discussion}

When the opportunity cost of producing As and $\bigcirc \mathrm{s}$ is low, our participants consistently produce (A) s instead of $\mathbb{C}$. They also discover how much time to devote to $\mathbf{A}$ production and how much to $\bigcirc$ production in order to maximize their own (A) output. Because production time is rivalrous, the opportunity cost of producing "too many" As or "too few" $\bigcirc$ s, or vice versa, is clear-they make fewer valuable (As. Likewise, the benefit of producing closer-to-optimal quantities of $\mathbf{A s}$ and $\bigcirc \mathrm{s}$ is apparent-they make more valuable (A).

When opportunity costs are low, our participants always (6 out of 6 times) achieve Marshallian internal economies. However, Marshallian external economies are much more hit-or-miss. External economies drive economic growth, so understanding how and why they emerge - and why they sometimes fail to emerge - is critical. Our experiment illustrates how ideas about costs and values and bounded rationality explain why external economies do and do not emerge.

"their A's aren't any cheaper tho so don't waste your time there"

- Khaki, Selection 2

Not only is Khaki not aware that Teal's As are indeed cheaper, he takes the inverse to be true when it is, in fact, false. Khaki's view of his environment is colored by his personal production possibilities, from which he cannot escape to consider alternative production arrangements. He needs a new idea! Khaki stays mired in autarky until Brown offers and Accounting, or across Selection and Accounting. All eight tests are Wilcoxon rank-sum tests, and all p-values exceed 0.20 . 
"extra" As from the Internal Market. A new idea comes to Khaki, he replies "we'll give you cents," and Selection 2's External Market finally takes off (see Figure 9b).

No agent in our experiment-Teal included - is instructed that Teal has increasing returns for As. In our experiment, as in the naturally occurring world, people have to discover the costs of alternative production arrangements. Marshall (1890, IV.X.7) famously comments that in close proximity "mysteries of the trade become no mysteries... if one man starts a new idea, it is taken up by others and combined with suggestions of their own; and thus it becomes the source of further new ideas." We do see ideas diffusing from one person to another in our experiment, yet even in our stylized environment, Marshall's evocative prose glosses over the difficulties of acquiring new ideas about the cost of more extensive specialization.

"i can't make your product so idk if trading is worth it"

- Teal, Learning 3

Teal's As are valuable to Pink, Gray, and Khaki, only she does not know this. Because she cannot sell Red As herself, she assumes that her As have no value in the External Market. Teal views her environment through the narrow lens of her own selling possibilities. She needs a new idea! Unfortunately, she never has one, and she is not given one, so Learning 3's External Market never takes off (see Figure 7b).

Pink, Gray, and Khaki each know how to combine As and $\mathrm{s}$ to make Red As, but somehow Teal has to see how her As can be valuable to the External Market agents. Teal needs an idea about the value of alternative production arrangements. As with innovation generally, to transform production, firms must be able to "identify, assimilate, and exploit knowledge from the environment" (Cohen and Levinthal, 1989, pg.569). Whether a firm has one employee or many, someone in the firm, or some group within the firm, must have an idea of how valuable more extensive specialization is. 
"we're fine the way we are; we have it figured out"

- Brown, Selection 5

In the period in which Brown says this, Selection 5 participants earn only $69 \%$ of possible Internal Market earnings and just 27\% of possible External Market earnings. In autarky, understanding the rivalry of time in the production of $\mathbf{A s}$ and $\mathbf{s}$ is crucial for profitable Red A production. But specialization flies in the face of this calculus. To form the idea to specialize, agents have to override their conception of time as rivalrous and see how their time can complement others' production time when they produce just one input.

Bounded rationality, specifically the "calculus of integrated production," is a particularly strong barrier to external economies in our External Markets. Through Period 20, Pink, Gray, and Khaki only receive feedback about autarky and the tradeoffs to producing As and s. After Period 20, they should ignore the rivalry of time, but the calculus of integrated production that serves them well early on, is later a barrier to specialization. In Selection 1, Brown notices that Pink sees the world differently:

$\begin{aligned} & \text { Brown } \text { you guys don't specialize? } \\ & \text { Pink } \text { what does that mean } \\ & \text { Brown } \text { you all have } 10 \text { production time right } \\ & \text { Pink } \text { no were all the same } \\ & \text { Brown } \text { i'll come back } \\ & \text { Purple } \text { [Brown walks away and up to Purple] } \\ & \text { Brown } \quad \text { i don't think any of them specialize } \\ & \text { Brown } \quad \text { all of them just produce what's good for them }\end{aligned}$

Pink lives in a naturally occurring world of 'specialization,' but in the context of the experiment it is a foreign concept. Pink has an idea that Red As are made by making both As and s. He never specializes because the idea of specialization never comes to him. Pink's situation calls to mind Allyn Young's cheeky observation that "the human material which has to be used [to extend specialization] is resistant to change" (1929, pg.534). 


\section{Conclusion}

Here is a story: Someone creates new knowledge and someone comes up with an idea to use the knowledge to create a novel intermediate good. Firms acquire the intermediate good and use it to make their own production processes more efficient. This is a happy story of external economies spurring economic growth. But it is only rosy when firm boundaries evolve. Imagine a counterfactual world where new ideas do not rearrange firm boundaries. In this absurd world, General Motors makes their own transistors and Fairchild Semiconductor makes their own cars.

When firm boundaries are rigid, economic growth staggers. Saxenian (1994) contrasts Silicon Valley's growth with the decline of Massachusetts' Route 128. According to Saxenian, Silicon Valley promoted "learning and flexible adjustment among specialist producers of a complex of related technologies," whereas Route 128 was "dominated by a small number of relatively integrated corporations... independent firms that internalize a wide range of productive activities" (Saxenian, 1994, pp.2-3).

Our experiment illustrates how economic growth falters when firm boundaries do not evolve to reflect external economies, that is, when the division of labor limits the division of labor. This limit is not the physical means for combining inputs into outputs, but the dearth of novel ideas about costs and profit possibilities never before seen. Ideas can melt firm boundaries and stimulate economic growth, but they can also crystallize such boundaries and flatline growth. Allyn Young (1928, pg.533) recognized the importance of fluid firm boundaries: "Every important advance in the organisation of production. .. alters the conditions of industrial activity and initiates responses elsewhere in the industrial structure which in turn have a further unsettling effect." Ideas unite growth theory and the theory of the firm, and ideas are why the division of labor is limited by the division of labor is no mere tautology. 


\section{References}

Alchian, Armen. "Uncertainty, evolution, and economic theory." Journal of Political Economy 58, no. 3 (1950): 211-221.

Alchian, Armen, and Harold Demsetz. "Production, information costs, and economic organization." The American Economic Review 62, no. 5 (1972): 777-795.

Cohen, Wesley, and Daniel Levinthal. "Innovation and learning: the two faces of R\&D." The Economic Journal 99, no. 397 (1989): 569-596.

Coase, Ronald. "The nature of the firm." Economica 4, no. 16 (1937): 386-405.

Crockett, Sean, Vernon Smith, and Bart Wilson. "Exchange and specialisation as a discovery process." The Economic Journal 119, no. 539 (2009): 1162-1188.

Demsetz, Harold. "The theory of the firm revisited." Journal of Law, Economics, $E$ Organization 4, no. 1 (1988): 141-161.

Feltovich, Nick. "Nonparametric tests of differences in medians: Comparison of the WilcoxonMann-Whitney and robust rank-order tests." Experimental Economics 6, no. 3 (2003): 273297.

Marshall, Alfred. Principles of Economics. 8th ed. London: Macmillan, 1920/1992.

McCloskey, Deirdre. The Bourgeois Virtues: Ethics for an Age of Commerce. Chicago: University of Chicago Press, 2006.

McCloskey, Deirdre. Bourgeois Dignity: Why Economics Cant Explain the Modern World. Chicago: University of Chicago Press, 2010.

McCloskey, Deirdre. Bourgeois Equality: How Ideas, Not Capital or Institutions, Enriched the World. Chicago: University of Chicago Press, 2016.

Rosenberg, Nathan. "Factors affecting the diffusion of technology." Explorations in Economic History 10, no. 1 (1972): 3-33.

Romer, Paul. "Increasing returns and long-run growth." Journal of Political Economy 94, no. 5 (1986): 1002-1037.

Saxenian, AnnaLee. Regional Advantage: Culture and Competition in Silicon Valley and Route 128. Cambridge, MA: Harvard, 1994.

Smith, Adam. An Inquiry into the Nature and Causes of the Wealth of Nations. Chicago: University of Chicago, 1776/1976.

Thackray, Arnold, David Brock, and Rachel Jones. Moore's Law: The Life of Gordon Moore, Silicon Valley's Quiet Revolutionary New York: Basic Books, 2015.

Williamson, Oliver. "The vertical integration of production: Market failure considerations." The American Economic Review 61, no. 2 (1971): 112-123.

Young, Allyn. "Increasing returns and economic progress." The Economic Journal 38, no. 152 (1928): 527-542. 


\section{Appendix - Experiment Instructions}

This appendix contains the complete instructions for the experiment.

\subsection{Opportunity Cost and External Instructions}

\section{Welcome}

This is an experiment in the economics of decision making. The instructions are simple, and if you follow them carefully and make good decisions you can earn a considerable amount of money which will be paid to you privately in CASH at the end of the experiment.

In this experiment you will be represented by the <Teal, Green, etc. $>$ avatar you see in the middle of the screen. You and the $<\mathbf{3} / \mathbf{6}>$ other people in the experiment each have the ability to move around the environment. The experiment will consist of many periods each lasting $<\mathbf{2 1 0 / 1 9 0 / 1 7 0 ~}>$ seconds.

\section{Movement}

You can move around the environment by left clicking on the spot you wish to move to (try clicking in the green grassy area now). Notice that a red circle marks the spot your avatar is moving towards. When the experiment begins, you can see the other people who are also moving in the same environment.

In the top left portion of the screen there is a mini map that displays the virtual world and your current location represented by a stick figure.

\section{Phase 1: Production Time}

In the first phase of a period, avatars decide how to allocate $\mathbf{1 0}$ seconds of production time

among three options: As, $\bigcirc$ s, and cents. As and $\bigcirc$ s are inputs to producing (As, which can be sold for cash in the next phase of the period. Time spent on cents is converted into 
immediate cash.

To produce As, walk over to an A symbol and right click on it. Do this now and type in 3.9 seconds.

Now walk over to a $\bigcirc$ symbol and use 3.9 more seconds of production time to produce circles. Do this now.

Different people may be able to produce different amounts of As and $\bigcirc$ s.

Finally, walk over to a $\$$ symbol and use 2.2 seconds to produce cash. Do this now.

Each avatar can move $\mathbf{A s}, \bigcirc$ s, and cents from their inventory to another avatar. To do so, right click on another avatar, choose the number of items to move, and click the Send button. Move $1 \mathbf{A}$ and $1 \bigcirc$ to the blue avatar on your screen. Do this now. (To cleanly select the blue avatar walk into the open green area.)

If you have both As and $\bigcirc$ s, then you can use them to produce As.

For each $\mathbf{A}$ you will need $\mathbf{1} \bigcirc$ to produce $\mathbf{1}$ (A). Walk over to a $\mathbf{A}$, right click on it, and type in the number of (A) s you would like to produce. Do this now.

\section{Phase 2: Selling A}

Phase 1 lasts $<\mathbf{8 0} / \mathbf{7 0}>$ seconds. When Phase 1 ends, robot buyers will arrive to purchase (A) s at the bottom of the screen. Each avatar can post a price that will be displayed in a sign of the same color as the avatar. To post a price, type a price into the box on the right side of the screen and click the Update Price button. No buyers will purchase at a price greater than 13.9 cents. Enter a price now.

You can update your price at any time. Your most recent price will be used until you 
update it.

To be able to sell you must be near your sign with the price in it. Walk down to your sign now. The buyers will continue to arrive randomly for $<\mathbf{3 0} / \mathbf{2 5} / \mathbf{2 0}>$ seconds. Each buyer has a willingness to pay for a unit. When a buyer appears, it will purchase one unit from the lowest priced seller. If the lowest price is greater than the buyers willingness to pay, then the buyer will not purchase a unit.

When the seller with the lowest price has sold all of their units, the buyer will go to the next lowest price seller (provided the price is less than its willingness to pay).

\section{Phase 3: Chat}

Every person in the experiment may chat during any phase. The final phase of $<\mathbf{2 0} / \mathbf{1 5} / \mathbf{1 0}>$ seconds is reserved just for chatting. Type your messages at the bottom of the screen and then press ENTER or click the Chat button. Your chat will appear next to your avatar. Do this now.

You are free to discuss any and all aspects of the experiment, with the following exceptions: you may not reveal your name, discuss side payments outside the laboratory, or engage in inappropriate language (including such shorthand as 'WTF'). If you do, you will be excused and you will not be paid.

\section{Summary}

This is the end of the instructions. The important points are:

(1) During Phase 1 avatars can produce $\mathbf{A s}, \bigcirc \mathrm{s}$, or cents. If an avatar has both $\mathbf{A s}$, s, an avatar can also produce (A).

(2) During Phase 2 avatars can sell (A) to buyers, as long as the avatars are next 


\section{to their sign.}

(3) During Phase 3 avatars can chat until the next period begins. Every 5 th period the chat phase will be longer, lasting $<\mathbf{8 0} / \mathbf{7 0}>$ seconds.

(4) Each cent in the experiment is worth US1\$, which will to be paid to you privately in cash at the end of the experiment.

If you have any questions, please raise your hand and a monitor will come by to answer them. If you are finished with the instructions, please click the Start button. The instructions will remain on your screen until everyone has clicked the Start button. We need everyone to click the Start button before we can begin.

\subsection{Additional Learning Instructions}

\subsubsection{Instructions for New Group}

In a moment you will be led into the laboratory and seated at a carrel with someone who has been participating in the experiment. You will assume control of the avatar on the computer screen, but the other person alone will receive all earnings for the next several periods of the experiment.

You are free to ask the person in your carrel questions about the experiment. Do not talk to people in other carrels, and please do not talk so loudly that people in other carrels can overhear you.

After a while, the experiment will pause. The other person will then exit the lab to be paid his or her total earnings in cash. You will then carry on the experiment and will receive all earnings from that point on. 
If you have any questions at any time, please raise your hand and a monitor will come to answer your question privately.

\subsubsection{Instructions for Old Group}

The experiment will resume shortly after another person enters the lab, sits down next to you, and assumes control of the keyboard and mouse. This person will control the avatar, but you alone will receive all earnings.

You may give verbal directions on all features of the experiment. Make sure the new person knows how to produce, transfer items, and update prices. Please do not talk so loudly that people in other carrels can overhear you.

After a while, the experiment will pause again. You will then exit the lab to be paid your total earnings, including the $\$ 7$ show-up payment, in cash. The new person will carry on the experiment and they will receive all earnings from that point on.

When you have finished reading these instructions, move to the other seat in your carrel, and click the Start button.

\subsection{Additional Selection Instructions}

\subsubsection{Buyout Offer Decision Screen}

You now have the option to produce As and $\bigcirc$ s using the other peoples allocations of production time. If you exercise this option, you will be the only person who can produce and sell (A) s. In exchange for this capability, you will have to pay the other people a fixed amount of money each period. After the selling phase ends, the software will automatically transfer the following amounts from your earnings to the other people: 


\section{$<$ Salaries $>$}

If you choose to "buy out" the other people, you will have the option of deciding which type of production time to use to produce $\mathbf{A s}$ and $\bigcirc$ s. When you right click on the $\mathbf{A}$ or the $\bigcirc$, use the radio button to select either Teal production time or the combined Green/Purple/Brown production time.

\subsubsection{Buyout Offer Wait Screen}

Another person in the experiment is being offered the option to produce As and $\bigcirc$ s using your production time. This also means that only he or she will produce and sell (A)s.

In exchange for this capability, he or she will pay you a fixed amount of money each period. After each selling phase ends, the software will automatically transfer $<$ Salary $>$ \& to you.

\subsubsection{Pink, Gray, and Khaki Wait Screen}

Please wait patiently as other participants make a decision. The experiment will resume shortly.

\subsection{Additional Accounting Instructions}

\section{Welcome}

This is an experiment in the economics of decision making. The instructions are simple, and if you follow them carefully and make good decisions you can earn a considerable amount of money which will be paid to you privately in CASH at the end of the experiment.

In this experiment there are two types of people: producers and advisers. You are are $<$ a producer/an adviser $>$. Each adviser reviews data to advise one and only one producer. 
<You/Your producer> will be represented by the <Teal, Green, etc.> avatar you see in the middle of the screen. Each producer has the ability to move around the environment. The experiment will consist of many periods each lasting $\mathbf{1 7 0}$ seconds.

\section{Movement}

$<$ You/Your producer $>$ can move around the environment by left clicking on the spot $<$ you wish/he or she wishes $>$ to move to (try clicking in the green grassy area now). Notice that a red circle marks the spot <your/your producer's > avatar is moving towards. When the experiment begins, <you/the producer > can see the other avatars who are also moving in the same environment.

In the top left portion of the screen there is a mini map that displays the virtual world and <your/your producer's > current location represented by a stick figure.

$<$ You are/Your producer is $>$ free to discuss any and all aspects of the experiment, with the following exceptions: no one may reveal his or her name, discuss side payments outside the laboratory, or engage in inappropriate language (including such shorthand as 'WTF'). If anyone does, he or she will be excused and will not be paid his or her experiment earnings.

\subsubsection{Final Instructions for Producers}

Your adviser has reviewed the instructions that you have just seen. The adviser's sole task is to review the data from the experiment and advise you. You may chat with your adviser throughout the experiment using a separate window on your screen. If the chat window is not yet visible, it will show shortly.

Your total earnings will be split each period with the adviser: $\mathbf{5 0 \%}$ for you and $\mathbf{5 0 \%}$ for 
the adviser.

\subsubsection{Final Instructions for Advisers}

You have now reviewed the instructions that your producer is reading. This screen is the one that you will use for the experiment. Notice that you can see what your producer sees in the green grassy area.

Your sole task is to review the data from the experiment and advise your producer. Your producer's total earnings will be split each period with you: $\mathbf{5 0 \%}$ for the producer and $50 \%$ for you.

You may chat with your producer throughout the experiment using the chat box in the upper left portion of the screen. Please type something now to your producer.

To view data, each period you will need to click on a button. Click the Show Production

button now. Use the check boxes at the bottom of the screen to display how much your producer produces for the seconds used. Hover your mouse over a data point and the graph will display the precise amount of seconds that were used to produce As, $\bigcirc \mathrm{s}$, or cents.

The other buttons display tables of data. Click on the What's This? button in the table for a description of the data. Do this now. 